\title{
REVIEW
}

\section{Use of functional imaging across clinical phases in CNS drug development}

\author{
D Borsook $k^{1,2,3,4,5,6}$, L Becerra ${ }^{1,2,3,4,5,6}$ and M Fava ${ }^{2,4,6}$
}

The use of novel brain biomarkers using nuclear magnetic resonance imaging holds potential of making central nervous system (CNS) drug development more efficient. By evaluating changes in brain function in the disease state or drug effects on brain function, the technology opens up the possibility of obtaining objective data on drug effects in the living awake brain. By providing objective data, imaging may improve the probability of success of identifying useful drugs to treat CNS diseases across all clinical phases (I-IV) of drug development. The evolution of functional imaging and the promise it holds to contribute to drug development will require the development of standards (including good imaging practice), but, if well integrated into drug development, functional imaging can define markers of CNS penetration, drug dosing and target engagement (even for drugs that are not amenable to positron emission tomography imaging) in phase l; differentiate objective measures of efficacy and side effects and responders vs non-responders in phase II, evaluate differences between placebo and drug in phase III trials and provide insights into disease modification in phase IV trials.

Translational Psychiatry (2013) 3, e282; doi:10.1038/tp.2013.43; published online 16 July 2013

\section{Introduction}

As noted in a historical review on drug development, the process has evolved from a chemistry-based process to integrating pharmacology and clinical sciences to the contributions of molecular biology and genomics. ${ }^{1}$ However, the complexity of the brain makes central nervous system (CNS) drug discovery a real challenge. In the past, even with significant investment in basic neuroscience, the majority of clinical trials have failed to translate into measurable clinical benefit. Notwithstanding the enormous developments in neuroscience, systems neurobiology, nuclear magnetic resonance (NMR) imaging in health and disease are clearly making their mark in questioning new approaches to drug development. With the advent of new techniques in functional neuroimaging, the ability to evaluate disease state and drug effects on neural systems in clinical populations has opened the door to adopting new approaches to CNS drug development particularly in clinical trials.

Over the past few decades, CNS drug development has been hampered by countless negative and failed double blind, placebo-controlled trials - trials that have failed to confirm the expected superiority of both novel and standard compounds over a placebo condition. Negative findings with promising new agents have often led to premature shelving of such compounds and many large pharmaceutical companies have gradually abandoned their focus on CNS drug development because of the perception that trials in this area are 'risky,' given the greater than $50 \%$ of failure in adequately powered trials. ${ }^{2}$ These negative trials have also caused delays in bringing new treatments to the market, increased costs of drug development, and, in some cases, Food and Drug Administration (FDA) decisions not to approve new treatments ('for the preponderance of negative data'). An analysis in JAMA ${ }^{3}$ of 75 double-blind antidepressant trials, which had been conducted among patients with major depressive disorder and had been published between January 1981 and December 2000, showed that the response to placebo was often substantial and progressively increasing, with a significant positive relationship between year of publication and response rate. The gradual increase in placebo response rates across psychiatric disorders is a worrisome phenomenon, which has had a dramatic impact on the clinical development of new therapeutic agents. The two biggest factors that contribute to the extremely high rate of failures of CNS clinical trials are misclassification of study subjects (for example, the patients do not have the disease under investigation or have much milder forms than those required) and the excessive placebo response. These issues are highly salient since, while there remains a high demand for new and effective treatments for CNS disorders (for example, depression, pain, Alzheimer's disease, seizure disorders and so on),

\footnotetext{
${ }^{1}$ Center for Pain and the Brain, MGH, Children's and Mclean Hospitals, Harvard Medical School, Boston, MA, USA; ${ }^{2}$ Clinical Trials and Network Institute (CTNI), Department of Psychiatry, Massachusetts General Hospital, Boston, MA, USA; ${ }^{3}$ Department of Anesthesia and Critical Care, P.A.I.N. Group, Boston Children's Hospital, MGH, Harvard Medical School, Waltham, MA, USA; ${ }^{4}$ Department of Psychiatry, MGH, Harvard Medical School, Boston, MA, USA and ${ }^{5}$ Department of Radiology, MGH, Harvard Medical School, Boston, MA, USA

Correspondence: Dr D Borsook, Department of Anesthesia and Critical Care, P.A.I.N. Group, Boston Children's Hospital, MGH, Harvard Medical School, 9 Hope Avenue, Waltham, MA 02453, USA.

E-mail: david.borsook@ childrens.harvard.edu

${ }^{6}$ These authors contributed equally to this work.

Keywords: brain; drug development; drugs; functional imaging; networks

Received 20 February 2013; accepted 15 March 2013
} 
the risk is such that many of the large pharmaceutical companies have withdrawn from this drug development arena. The lack of new drugs speaks to a problem that exists in the field-that old practices do not work and that new and innovative approaches are urgently needed. ${ }^{4}$ Indeed some have termed these difficulties as contributing to 'the death of CNS drug development . ${ }^{5}$ Large pharmaceutical company pullout of CNS indications is leaving a large gap in the CNS drug development line and the clinical unmet need will require other adaptive strategies such as smaller biotech or the advent of better approaches to discover and develop new agents for treating disorders of the brain and mind. An imaging approach across drug development (including proof of concept paradigms) ${ }^{6}$ will help drug discovery as will fully integrate the early development side (mainly bottom-up) with clinical trials (mainly top-down).

\section{Subjective ratings in CNS disorders}

Subjective ratings are highly variable. Yet this is by and large what has become a major determinant of outcome in CNS trials, which often rely on clinician-rated measurements that are subjects to various biases. It is a complex issue confounded by placebo effect, the lack of effect size, the undulating or changing nature of the disease. Inter-individual differences relate to biology, disease state, psychological phenomena and the consistency of the instrument/s used to measure outcomes. Even for the same stimulus, different scales have differences in reliability. ${ }^{7,8}$ In these cases, we are not even considering an individual's ability (education, cognitive ability -innate or due to disease such as neurodegenerative conditions; depression and so on) that may bias the outcome. Inadequate response may also be a concern that relate to dosing, duration of treatment and other factors. The harbinger of clinical trial failure has included high placebo responses. Many contributing factors to high placebo response rates observed in CNS clinical trials have been identified, such as diagnostic misclassification, issues concerning inclusion/exclusion criteria, outcome measures' lack of sensitivity to change, measurement errors, misclassification of treatment outcome, waxing and waning of the natural course of illness, regression toward the mean phenomenon, study designs fostering high patient and clinician expectations, nonspecific therapeutic effects and high attrition rates. ${ }^{9}$ Three of these elements are thought to represent the most critical factors in yielding high placebo response rates: diagnostic misclassification, misclassification of treatment outcome and study designs fostering high patient and clinician expectations. Clinical trial design is becoming more sophisticated including enrichment trials (see Fava et al. ${ }^{10}$ and Chen et $\left.a .^{11}\right)$. New approaches include the 'Sequential Parallel Comparison Design', 9 suitable for double-blind, placebocontrolled trials in CNS disorders. This design is aimed at reducing both the overall placebo response rate and the sample size required for such trials. The basic idea is to have two phases of treatment. The first phase involves an unbalanced randomization between placebo and active treatment with more patients randomized to placebo. In the second phase, non-responders treated with placebo are randomized to either active treatment or placebo. As patients on the second phase have already 'failed placebo', their placebo response is expected to be reduced. The analysis pools the data from both phases in order to maximize power and reduce the required sample size (see http://clinicaltrials. gov/ct2/show/record/NCT01318434). Thus far, three Sequential Parallel Comparison Design trials of CNS compounds have been completed and published, yielding weighted averages of placebo response rates markedly lower than those observed in standard designs. ${ }^{12,13}$

Given the state of the art, there would appear to be some new impetus to utilizing new ${ }^{14}$ technologies to help improve trial information and outcomes. One such approach that is being applied with greater seriousness is that of functional imaging of brain systems. Here we review the nature of how imaging may contribute across Clinical Trials both as a contributor to new information and also providing insights into integration of information across phases of clinical trials. We have termed this as imaging in Drug Development.

\section{Current issues in CNS drug development and potential opportunities through imaging}

Capturing data of functional effects of drug action in the living human brain of healthy volunteers or patients bring with it new opportunities to understand drug effects on CNS circuits in a manner that should transform CNS drug development. We discuss some of these processes across each phase (I-IV), noting some of the issues that are faced and provide support for how the use of imaging may either overcome or at least mitigate some of these hurdles. The major contributions relate to objectifying information in a rapid and specific manner. Integration of imaging processes across the drug development process can determine short-term effects (for example, CNS penetration and dosing), intermediate effects (for example, targets for symptom relief, possible side effects) and long-term drug effects (for example, disease modification). As suggested in the discussion below, although imaging may find useful applications across each phase, there are dominant roles suggested for phase I (evaluative imaging); phase II (effective imaging-disease targeting); phase III (definitional imagingdiminishing the variance of trials, defining responders vs nonresponders; disease modification).

\section{Imaging concepts}

Details of imaging methods can be found elsewhere but a few concepts that relate to what can be measured are noted in Box 1.

\section{Phase I}

Phase I trials 'test an experimental drug or treatment in a small group of people $e^{20-79}$ for the first time to evaluate its safety, determine a safe dosage range and identify side effects' (www.clinicaltrials.gov). Few drugs (approximately 1 in 10) that are evaluated in preclinical phases make it to phase I testing in humans. First-in-human (FIH) doses are clearly fraught with how best to protect subjects. ${ }^{35}$ Once a drug (new chemical entity) is approved for FIH by a federal agency (for example, the FDA or the European Medicines Agency 
Box 1: Imaging concepts in measures of drug effects

Bold: The blood oxygenation level dependence is the main approach to measure brain activity through fMRI. Based on an interplay of local brain blood flow and volume associated with neuronal activity assesses indirectly the level of neuronal responses to stimuli, such as sensory or pharmacological inputs. Effectiveness of pharmacological treatments in patients can be evaluated across CNS disease-related function (examples: see refs. ${ }^{15-19}$ ) or differentiation of drugs ${ }^{20,21}$ or drug dosing 22,23).

Resting state networks (RSNs): One of the exciting development is the use of BOLD to measure RSNs; these are lowlevel spontaneous fluctuations in the BOLD signal during rest that reflect the neuronal baseline activity of the brain. ${ }^{24}$ As such, they can differentiate disease state or drug effects. ${ }^{25-27}$ Connectivity measurements: Repeated BOLD measurements of brain activity have been utilized to determine brain networks associated with basal brain function as well as alteration in the disease state or drug effects. ${ }^{22,28}$ Recently, series of basal networks in the healthy state have been identified and their modification in different diseases established. Inspection of the functional role of each of these networks permits correlate observed behavioral outcomes in diseases and the concomitant correction of these changes when disease is resolved or ameliorated.

Pharmacological fMRI (phMRI): phMRI is variant of $\mathrm{AMRI}$ and refers to a particular approach of $\mathrm{fMRI}$ in which the specific brain response to a CNS-acting drug is measured. ${ }^{29}$

Arterial spin labeling ( $A S L$ ): Arterial spin labeling is a technique that allows the measure of perfusion without the use of external agents (such as contrast agents). ${ }^{30}$ More quantitative than BOLD but with less spatial and temporal resolution permits to capture snapshots of basal perfusion and if necessary brain activity. Quantitative pharmacological effects on brain activation can be evaluated using this approach.

Morphometric measurements: Voxel base measures (VBM) and surface base methods allow the examination of changes in brain structures in volume and thickness. Such measures have shown that, in the disease state, dilation and shrinkage occur and that treatment can resolve these changes. Disease state $^{31}$ and long-term effects of drugs on brain morphometry may be evaluated using this approach. ${ }^{32}$

Diffusion tensor imaging (DTI): DTI is an MRI technique that measures the apparent diffusion coefficient of water molecules in tissue. Improvements in the ability to capture DTI data and analysis tools have resulted in new measurements of white matter integrity as well as determine potential tracks among different brain regions. Drugs (for example, ketamine or opioids) may produce changes in white matter tracts ${ }^{33}$ that may reflect either direct actions or effects on neuronal bodies. Magnetic resonance spectroscopy (MRS): MRS provides measures of brain neurochemistry (for example, glutamate, gamma-amino-butyric acid and so on). Chemical measures can provide insights into drug modulation of excitatory and inhibitory neurotransmitters systems and the potential to predict responders and non-responders (see Harris et al. ${ }^{34}$ ).
(EMA)), initial phase I studies are conducted, usually in healthy volunteers, to determine safety and dosing (viz., toxicity, pharmacokinetics and metabolism). More recently, phase I studies are beginning to include subjects with the CNS disease that is ultimately targeted by the compound under development. When this happens, it becomes critical to ensure that subjects do suffer from the CNS disease under investigation, it is also critical to provide greater information on the CNS effects of the compound studied and subjective ratings are often grossly inadequate in providing information on CNS penetration and targeting. It is a this time and going forward, significant increases in costs are associated with drug development and processes that can provide objective data for go-nogo decisions are critical for efficient development programs. For those drugs with CNS indications, the additional focus on CNS-related processes is required (for example, CNS penetration). Clearly maximizing information at this and later stages of clinical trial, drug development is clearly desirable and warranted. As noted by Dresser, ${ }^{36}$ ethical issues are being spotlighted as translational science approaches are inevitably leading to increases in FIH trials.

CNS penetration and targeting. The blood-brain barrier can limit penetration of drugs into the $\mathrm{CNS}^{37}$ and effective measures of drug penetration into the CNS for CNS-acting drugs are clearly critical-both from the point of view of how much crosses the blood-brain barrier and how best to choose an effective dose to achieve effective/therapeutic levels. CNS-acting drugs can be measured for their penetration using cerebrospinal fluid levels or specific brain markers (for example, positron emission tomographic-based receptor ligands). In addition, positron emission tomography (PET) tracers can define drug targets (target engagement) within the brain. However, there are issues that the ligand-based approach does not provide: (1) functional responses to the drug effective engagement; (2) functional dose responses related to the drug of interest; and (3) for many drugs, the development of a specific ligand for PET is not possible. ${ }^{29,38}$

Imaging opportunity. Pharmacological magnetic resonance imaging (phMRI) allows for the direct (effects of drug on brain systems) and indirect (effects of drug on responses) evaluation of drug action in humans in early phase studies. ${ }^{29}$ Examples of phMRI use for evaluation of drugs in humans are numerous (examples of direct measures include buprenorphine; ${ }^{22}$ fosaprepitant; ${ }^{39}$ mirtazapine). ${ }^{40}$ It should be pointed out that simple phMRI activation, while it may confer some information of drug-brain (receptor/s) activation, the efficacy of the drug might depend more on functional connectivity of how the drug affects certain brain circuits. ${ }^{22,23}$ Thus, in a few patients important data on CNS penetration can be assessed. Taken into context with known pharmacokinetic and pharmacodynamic profiles, the time for changes in brain systems can also validate expected timelines for effective CNS 'functional dosing'. Here we define functional dosing as the minimal dose (or early dose effects) that produces significant activation or alteration in brain circuits. Thus, in a few subjects valuable early data can be obtained for most CNS-acting drugs in early or FIH trials. This is an initial but major opportunity for the utility of imaging to 
contribute to the clinical evaluation of CNS-acting drugs. This approach can be used early in clinical trials once an Investigational New Drug is obtained (without special preparation for PET ligands if these are possible); and where multiple receptor targets may be at play, such receptor-specific ligands are cannot be produced. Figure 1 shows details of the potential of the use of phMRI in defining CNS dosing and drug 'target/s'. To date a number of phase I imaging studies have employed true phMRI measures as reported in the literature (for example, see Upadhyay et al. ${ }^{22,23,41}$ ). Imaging could help in determining potential side effects as well as dosing to obtain desired effect. Specifically, in the use of combined PET—magnetic resonance imaging (MRI) systems, it will be possible to determine whether $50 \%$ receptor occupancy (with PET) produces the desired brain response (with functional MRI (fMRI)). Examples of fMRI in phase I are noted in the public domain (http://clinicaltrials.gov, see Table 1; see section 'Where we are now?' below). These include measures of acute effects of tetrahydrocannabinol on functional brain systems that included measures on reward and memory. In these studies, end points include PK/PD correlations of drug measures with brain function. The study of RO4917523 by Hoffman-La Roche is perhaps more indicative of the approach that is beginning to be used with phase I trials by the pharmaceutical industry. The compound is a negative modulator (antagonist) of the metabotopic glutamate receptor subtype 5 (mGluR5; GRM5). Here a new drug is compared with two other drugs and placebo in a randomized crossover trial as a safety efficacy trial in 25 healthy volunteers. The primary outcome is listed 'To evaluate the ability of fMRI to detect and characterize the effect of the three drugs on brain activity at rest and during emotional stimuli'; the secondary outcomes are noted as: (i) 'To evaluate the ability of other behavioral paradigms/scales to detect drug effects'; (ii) 'To correlate the fMRI measures with the clinical/behavioral measures'; and (iii) 'To investigate the safety of single doses of RO4917523 in healthy volunteers'. This study also provides an example of comparing a novel agent with currently marketed drugs.

Healthy vs patients. Why use healthy subjects in clinical trials? There are numerous issues relating to differences in healthy vs patients including altered brain neurobiology, differences in brain penetration across the blood-brain barrier, many patients having had other medications or on medications, and side-effect profile risks. Although there are some significant benefits to evaluating CNS drug effects in patients using imaging (noted below), most FIH trials are in healthy volunteers. These are usually small, dose-escalation trials to determine appropriate dose (based on safety and side effects) for use in future trials. ${ }^{42}$ In general, healthy subjects are used if there is little chance of patients obtaining benefit; and patients may be used when there is a good chance of benefit (for example, in some oncology trials).

Imaging opportunity. Imaging new drug candidate effects in healthy humans can provide data on networks affected by the drug (including those that are targeted for good effect and those systems that may be involved in side effects such as drowsiness, nausea and vomiting, addiction potential). Such

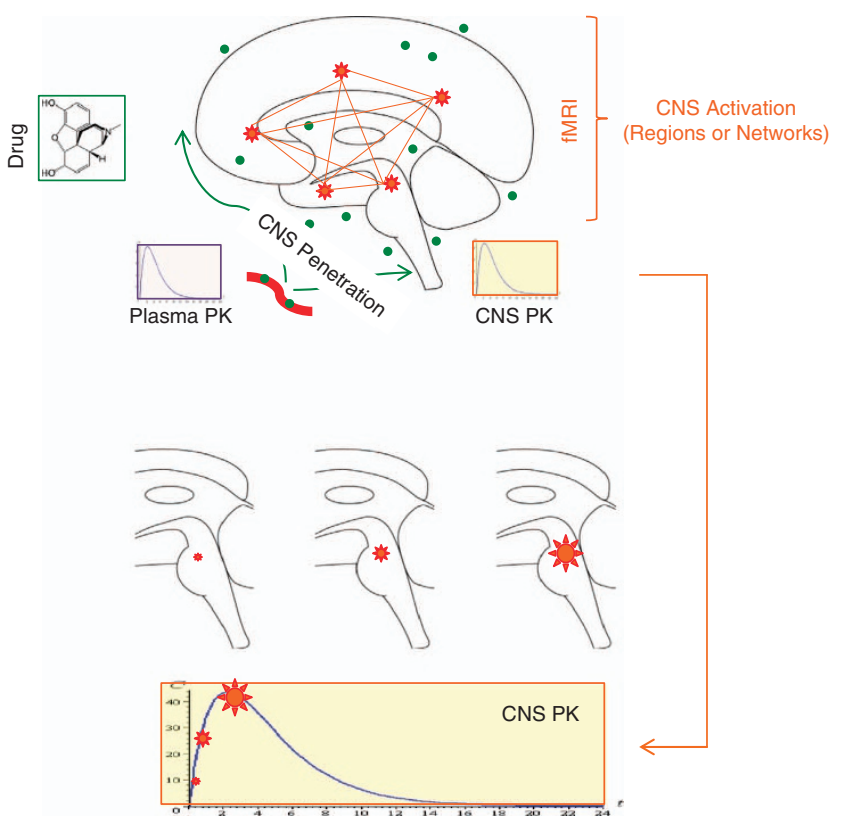

Figure 1 Specific outcomes for magnetic resonance imaging (MRI) imaging in phase I trials. Top: Measures of CNS penetration and brain activation. Bottom: Indirect measures of central nervous system (CNS) dosing. The latter can be evaluated in two ways-either through such modeling of effective increasing doses based on concentrations evolving to Cmax. Further functional MRI (fMRI) studies using different doses can further define effective dosing as defined by activation. Such dosing has been shown to differentiate drug activity. ${ }^{23} \mathrm{PK}$, pharmacokinetics.

data would provide a sound baseline for differences or similarities of the effects of the drug in a patient population (that could easily be integrated in phase II studies). For those who argue that phase I trials be conducted in patients who are targeted for the indication, the same principles applythrough the use of imaging, early definition of targets involved. In addition, neuroimaging could be used to independently validate the diagnosis of the CNS disorder in those instances where there is adequate sensitivity and specificity of the imaging tests. ${ }^{43-48}$ Figure 2 shows details of imaging data sets from healthy and patient populations that may provide useful information on the drug effect on normal and abnormal circuits. The issue is salient as much of the individual's brain may continue to have 'normal function' and thus a drug may act on these normal systems to contribute to its efficacy. The potential for imaging in early clinical trials is that it would seem to provide highly valuable additional data that currently cannot be easily assayed in other ways. Such data may provide information that may confirm the diagnosis of the CNS disorder, may indicate which networks are affected by the drug and may modify the future trail design before larger more expensive trials are implemented. In addition, early comparisons of drug effects in healthy and patients would seem to provide optimal data on drug dosing. For example, we and others have shown that fMRI can contribute to understanding optimal drug dosing for CNS effects and that the efficacy may depend on the brain functional connectivity not simply phMRI regional activation. ${ }^{22,23}$ One of the important missing pieces of data 
Table 1 Examples of CNS acting drug trials using imaging (data collected from clinicaltrials.gov)

\begin{tabular}{|c|c|c|c|c|}
\hline Drug (comparators) & Indication & Phase & Imaging modality & ClinicalTrials.gov identifier \\
\hline 1. Adalimumab & Rheumatoid arthritis & $\mathrm{NI}$ & fMRI & NCT01197144 \\
\hline 2. Alprazolam & General anxiety disorder & IV & fMRI & NCT00662259 \\
\hline 3. Amisulpride (Olanzapine) (Haloperidol) & Schizophrenia & IV & fMRI/DTI & NCT00419653 \\
\hline 4. AQW051 & Schizophrenia & i & fMRI & NCT00825539 \\
\hline 5. Aripiprazole (D-Cycloserine) & Autistic disorder & III & fMRI & NCT00198107 \\
\hline Aripiprazole & Autistic disorder & IV & fMRI & NCT01028820 \\
\hline Aripiprazole (Haloperidol) & Schizophrenia & i & phMRI & NCT01161277 \\
\hline 6. Atomoxetine & Methamphetamine abuse & 1 & fMRI & NCT01019707 \\
\hline Atomexitine (Methylphenidate) & ADHD & IV & fMRI & NCT01678209 \\
\hline Atomoxetine & ADHD & IV & fMRI & NCT00716274 \\
\hline 7. AZD6765 (Ketamine) & Major depression & i & fMRI & NCT01046630 \\
\hline 8. Botulinum toxin $A$ & Cerebral palsy & $\mathrm{I} / \mathrm{II}$ & fMRI & NCT00503620 \\
\hline 9. Buproprion (Escitalopram) & Depression & IV & fMRI/MRS & NCT01541475 \\
\hline Buproprion & Healthy & 1 & fMRI & NCT00205946 \\
\hline 10. CGRP & Migraine & $\mathrm{NI}$ & fMRI & NCT00363532 \\
\hline 11. Citrolam & Depression & $\mathrm{NI}$ & fMRI/MRS & NCT01568684 \\
\hline Citalopram & Autism spectrum disorders & I & fMRI & NCT00609531 \\
\hline Citalopram + mood Stab & Bipolar depression & $\mathrm{II} / \mathrm{II}$ & fMRI/PET & NCT00562861 \\
\hline 12. Cytokine** & Model of depression & 0 & fMRI & NCT00949845 \\
\hline 13. Delta9-tetra-hydrocannabinol & Addiction & I & fMRI & NCT00628706 \\
\hline 14. Desipramine & Irritable bowel syndrome & $\mathrm{NI}$ & fMRI & NCT00880594 \\
\hline 15. Desvenlafaxine & Depression & III & fMRI & NCT00888862 \\
\hline 16. Diacetylmorphine & Stress/healthy & $\mathrm{I} / \mathrm{II}$ & fMRI & NCT01174927 \\
\hline 17. Diazepam (Lorazepam) & Healthy & $\mathrm{NI}$ & fMRI & NCT00696033 \\
\hline 18. Donazepil & Alzheimer's disease & IV & fMRI & NCT00477659 \\
\hline Donazepil & Alzheimer's disease & $\mathrm{I} / \mathrm{II}$ & fMRI & NCT00408525 \\
\hline Donazepil & Fragile- $\mathrm{X}$ & 1 & fMRI & NCT00220584 \\
\hline 19. Duloxetine & Dysthymic order & IV & fMRI & NCT00360724 \\
\hline Duloxetine & Depression & IV & fMRI & NCT01051466 \\
\hline Duloxetine & Depression & IV & fMRI & NCT00532480 \\
\hline Duloxetine & Depression & IV & fMRI & NCT00889369 \\
\hline Duloxetine & Interoceptive awareness & IV & fMRI & NCT00337012 \\
\hline 20. Eszopiclone & Sleep/pain & IV & fMRI & NCT00414037 \\
\hline Eszopiclone & Depression & $\mathrm{NI}$ & fMRI & NCT00926653 \\
\hline 21. Exendin-4 & Alzheimer's disease & II & fMRI/Mroph & NCT01255163 \\
\hline 22. Fluoxetine & Depression & IV & $\mathrm{fMRI}$ & NCT00188942 \\
\hline Fluoxetine & Depression (children) & $\mathrm{NI}$ & fMRI & NCT00018057 \\
\hline Fluoxetine + olanzepine (olanzepine) & Depression & IV & $\mathrm{fMRI}$ & NCT00188942 \\
\hline Fluoxetine (children) & Depression & $\mathrm{NI}$ & fMRI & NCT00018057 \\
\hline Fluoxetine (children) & Depression & $\mathrm{NI}$ & fMRI & NCT01740726 \\
\hline 23. Glatiramer acetate (IFN- $\beta-1 a)$ & Multiple sclerosis & IV & fMRI & NCT00398528 \\
\hline 24. GSK561679 (Lorazepam) & Depression & l & fMRI & NCT00513565 \\
\hline 25. GW679769 (Alprazolam) & Social anxiety disorder & i & fMRI & NCT00332046 \\
\hline 26. GSK561679 (GW876008) (Alprazolam) & Social anxiety disorder & i & fMRI & NCT00555139 \\
\hline 27. GSK598809 & Food addiction & i & fMRI & NCT01039454 \\
\hline 28. Guanfacine Hydrochloride & ADHD & IV & fMRI & NCT01709695 \\
\hline 29. GW876008 & Irritable bowel syndrome & i & fMRI & NCT00376896 \\
\hline 30. Ketamine & Attentiveness & 1 & fMRI & NCT01165294 \\
\hline Ketamine & Depression & II & fMRI & NCT01135758 \\
\hline 31. Lamotrigine & Neuropathic pain & $\mathrm{NI}$ & fMRI & NCT00243152 \\
\hline 32. Leptin (Pramlintide) & Obesity & $\mathrm{NI}$ & fMRI & NCT00691158 \\
\hline 33. Leviracetam & Alzheimer's & II & fMRI & NCT01044758 \\
\hline Leviracetam & Mild cognitive impairment & II & fMRI & NCT01044758 \\
\hline 34. Levodopa & Alzheimer's disease & IV & fMRI & NCT00306124 \\
\hline Levadopa & Tourette's syndrome & $\mathrm{NI}$ & fMRI & NCT00634556 \\
\hline 35. Lidocaine & Healthy & $\mathrm{NI}$ & fMRI & NCT00725504 \\
\hline 36. Lithium (Quetiapine) & Bipolar mania & IV & fMRI & NCT00609193 \\
\hline Lithium & Bipolar disorder & IV & fMRI & NCT00596622 \\
\hline Lithium & Bipolar disorder & IV & Morphom & NCT01543724 \\
\hline Lithium & Multiple systems atrophy & II & fMRI (RSN) & NCT00097672 \\
\hline Lithium & Spinocerebellar ataxia 2 & II & fMRI(RSN)/Morph & NCT00998634 \\
\hline 37. Lidoderm & Back pain & IV & $\mathrm{fMRI}$ & NCT01515540 \\
\hline 38. Lisdexamfetamine & Bipolar depression & IV & fMRI & NCT01051440 \\
\hline 39. LY686017 (NK1 antagonist) & Alcohol craving & II & fMRI & NCT00310427 \\
\hline 40. Methylphenidate (children) & ADHD & IV & fMRI & NCT00778310 \\
\hline Methylphenidate & TBI memory & $\mathrm{NI}$ & fMRI & NXT00453921 \\
\hline 41. MDMA (3,4-Methylene dioxymethamphetamine & Addiction & I & fMRI & NCT01148342 \\
\hline 42. Milnacipran & Fibromyalgia & III & fMRI & NCT00793520 \\
\hline 43. MK3134 (Donezapil) & Cognition & 1 & fMRI & NCT00887601 \\
\hline 44. Morphine & Healthy & IV & fMRI & NCT01245244 \\
\hline 45. N-Acetyl cysteine & Schizophrenia & IV & fMRI & NCT01339858 \\
\hline 46. Nefazodone & Social anxiety disorder & IV & fMRI & NCT00231348 \\
\hline 47. Naproxen & Osteoarthritis & 0 & fMRI & NCT00830050 \\
\hline 48. Oxytocin & Autism & I & fMRI & NCT00263796 \\
\hline 49. Oxytocin & Social cognition & i & fMRI & NCT01606462 \\
\hline 50. Paracetamol & Healthy & I & fMRI & NCT01562704 \\
\hline Paracetamol & Pain/healthy & i & fMRI & NCT01562704 \\
\hline
\end{tabular}


Table 1 (Continued)

\begin{tabular}{|c|c|c|c|c|}
\hline Drug (comparators) & Indication & Phase & Imaging modality & ClinicalTrials.gov identifier \\
\hline Paracetamol & Osteoarthtriis & IV & fMRI & NCT01105936 \\
\hline 51. Paroxetine & PTSD & IV & fMRI & NCT00700999 \\
\hline Paroxetine & Depression & IV & fRMI & NCT00429169 \\
\hline 52. Pioglitazone & Cognition & 1 & fMRI & NCT01456117 \\
\hline 53. Pituitary adenylate cyclase-activating polypeptide-38 (VIP) & Migraine & $\mathrm{NI}$ & fMRI & NCT01471990 \\
\hline 54. Pramipexole (Amisulpride) & Obsessive compulsive disorder & i & fMRI & NCT00471588 \\
\hline 55. Pregabalin & Neuropathic pain & $\mathrm{NI}$ & MRS & NCT01180608 \\
\hline Pregabalin & Fibromyalgia & l & MRS & NCT00760474 \\
\hline Pregabalin & Anxiety & IV & fMRI & NCT00706836 \\
\hline Pregabalin (Tramadol) & Traumatic neuropathy & IV & fMRI & NCT00610155 \\
\hline 56. Quetiapine & Depression & IV & fMRI & NCT01200901 \\
\hline 57. Razadyne (Aricept) & Alzheimer's & IV & fMRI & NCT00369603 \\
\hline 58. Risperidaone & Autism & II & fMRI & NCT01171937 \\
\hline Risperidone & Autism spectrum disorders & II & fMRI & NCT01171937 \\
\hline 59. Rivastigmine & Alzheimer's & $\mathrm{NI}$ & fMRI & NCT00627848 \\
\hline 60. R04917523 (escitalopram) (methylphenidate) & Depression & Ila & fMRI & NCT01045083 \\
\hline 61. R05285119 & Healthy & l & phMRI & NCT01418963 \\
\hline 62. RPh201 & Vegetative state & $\mathrm{I} / \mathrm{II}$ & fMRI & NCT01438684 \\
\hline 63. Sapropterin & Phenylketonuria & $\mathrm{NI}$ & fMRI/DTI & NCT00730080 \\
\hline 64. Scopolamine (Donazepil) & Healthy/cholinergic function & $\mathrm{NI}$ & ASL & NCT01379001 \\
\hline 65. Sertraline & PTSD & IV & fMRI & NCT00391430 \\
\hline 66. Silbutramine & Obesity & 1 & fMRI & NCT00914212 \\
\hline 67. SYN115 & Parkinson's disease & II & fMRI & NCT00605553 \\
\hline 68. Valproate & Bipolar disorder & IV & Morphom/MRS & NCT00431522 \\
\hline 69. Varenicline & Alcohol addiction & $\mathrm{I} / \mathrm{II}$ & fMRI & NCT00695500 \\
\hline 70. Vyvanse & mTBI & III & fMRI & NCT01000064 \\
\hline
\end{tabular}

Abbreviations: ADHD, attention deficit hyperactivity disorder; ASL, arterial spin labeling; CGRP, Calcitonin-Gene-Related Peptide; DTI, diffusion tensor imaging; fMRI, functional magnetic resonance imaging; MRS, magnetic resonance spectroscopy; mTBI, mild traumatic brain injury; PET, positron emission tomography; PTSD, post traumatic stress disorder; RSN, resting state network; TBI, traumatic brain injury.

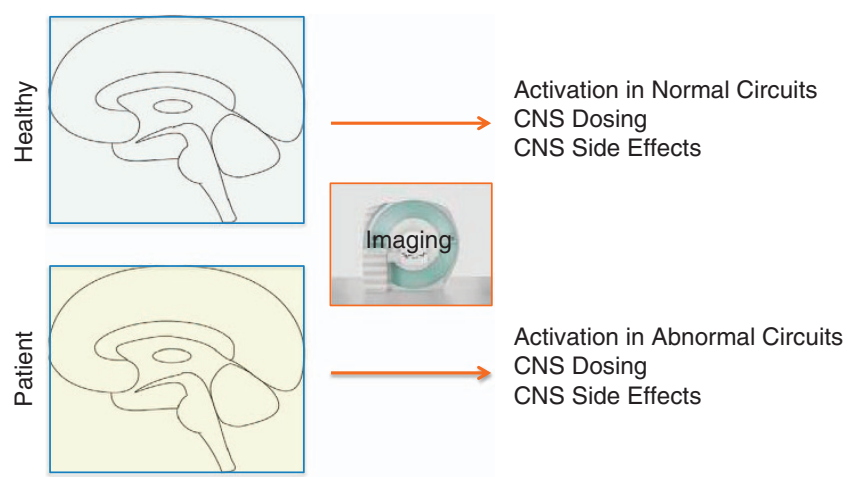

Figure 2 Imaging healthy subjects vs patient populations in phase I. Functional magnetic resonance imaging evaluation of drug measures using healthy subjects or patients in early phase trials (for example, ('1a') can provide information on central nervous system (CNS) penetration and dosing). However, the equivalence in the clinical population may not be the same because of numerous factors (disease state, prior drug effects, altered effects on specific circuits and so on). As noted below, the use of healthy subjects and later comparison in patients will further define the utility of early imaging for newly approved Investigational New Drugs. The later parallel and replicated study in patients will confirm or provide data to suggest finessing dosing for later trails.

will be the comparison in future studies of healthy vs patient data for the effects of drugs to determine the value of healthy subjects as has been evaluated previously for non-CNSacting drugs using a pharmacokinetic model. ${ }^{49}$ Imaging can provide this comparison in relatively few numbers of patients (Figure 2). Thus, imaging can provide a bridging process between the healthy and patient populations to determine appropriate dosing in the patient population (who differ from healthy controls) before designing phase II efficacy trials. ${ }^{50}$ This is particularly critical in CNS disorders such as major depressive disorder, where often half of the subjects are in the obese range of body mass index, in contrast to the typical leaner populations serving as healthy controls.

\section{Phase II}

In phase II trials, evaluation of the drug in patient populations is undertaken: 'The experimental study drug or treatment is given to a larger group of subjects $(100-300)$ to see if it is effective and to further evaluate its safety' (http://clinicaltrials. gov). Major issues here relate to measures of understanding efficacy rates, particularly, in the context that these trials are usually not that long in nature (see Figure 3). Without an objective marker, subjective ratings continue to be used, with consequences that include features such as large variance, poor inter-rater variability and rater biases. The diagnosis of most CNS disorders is based on the subjective interpretation of signs and symptoms on the part of the clinician. Even when 


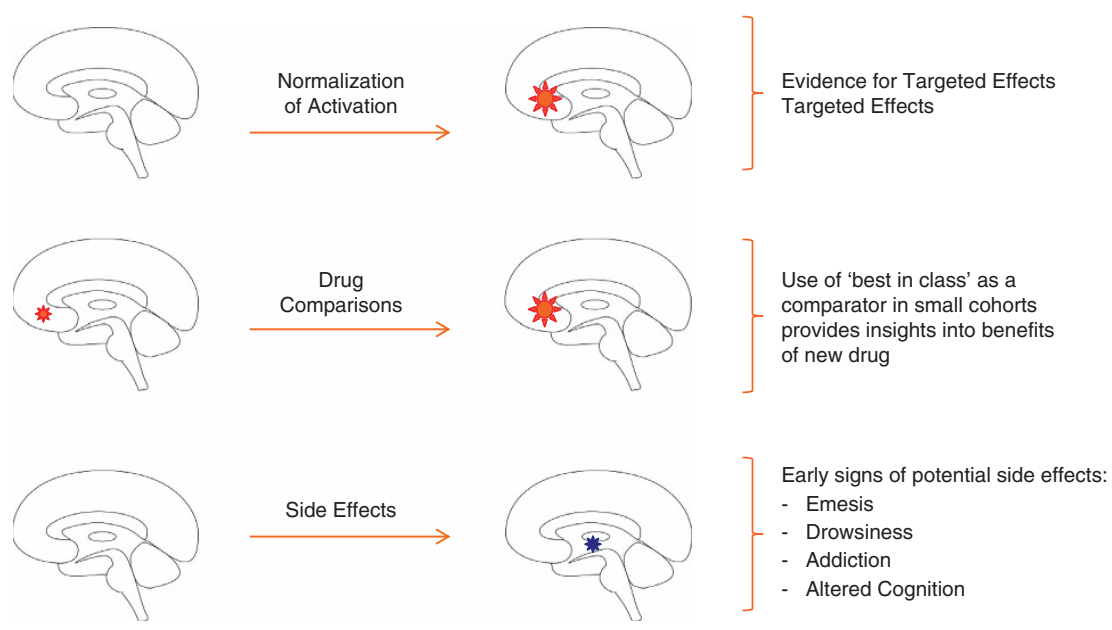

Figure 3 Magnetic resonance imaging (MRI) measures in phase II. Top: Normalization of circuits has been observed in a few functional MRI studies, consistent with behavioral effects. ${ }^{10}$ Middle: Comparative drug effects allows for a number of observations including (1) comparison with best in class; (2) comparison with known mechanism of action type drugs. Bottom: Side-effect profiles may be subclinical or not significant in smaller cohorts but present as potential issues that can be defined in early studies.

objective tests are used, such as electroencephalography in epilepsy and polysomnography in sleep disorders, there is often a risk of over inclusion of atypical forms of illness, which are more likely to have spontaneous fluctuations of symptoms and may inflate rates of placebo response. Site clinicians' biases to enroll subjects into trials, coupled with a system of incentives for Clinical Research Organizations to reward rapidity and not quality of enrollment, make clearly necessary the independent verification of diagnosis through centralized systems such as remote raters and/or remote reviews of diagnostic tests. Patients enrolled in CNS clinical trials often present with a heterogeneous group of symptoms representing several syndromes or subtypes, subsumed under the same diagnosis in the classification system. As a result, enrolled patients may not have the valid illness characteristics of interest to the particular study. The recently proposed SAFER interview method ${ }^{51}$ represents an effort to address the problem of diagnostic misclassification in clinical trials of psychiatric disorders. This method was developed to delineate a more symptom specific and ecologically valid approach to the identification of the valid patient for clinical trials, as clinical drug development needs to focus on the primary nosological entity likely to be affected by a new drug entity's mode of action. Neuroimaging may allow the remote validation of the appropriateness of the inclusion of study subjects and may confirm the diagnosis. Opportunities to evaluate circuit-based measures of efficacy, potential new indications, make comparisons across similar or competitive drugs, and defining measures of response (variance) can all contribute to the traditional drug development model. In phase II studies, patients may either be included in the overall study or smaller 'satellite' groups undergo imaging to determine a number of features of the drug including functional measures, evaluating sample size (that may change if specific imaging outcomes or measures are added), comparison with other drugs to get an understanding of potential competitive advantages and the like (discussed below). Phase II trials offer an ideal opportunity to integrate neuroimaging and new trial designs such as the Sequential Parallel Comparison Design, ${ }^{9}$ thereby providing an ability to evaluate novel therapies with greater confidence of the validity of conclusions, before their going into phase III trials. Examples of the use of NMR imaging in phase II include the GlaxoSmithKline evaluation of two doses 20 and $200 \mathrm{mg}$ of a Corticotrophin Releasing Factor 1 Receptor Antagonist on brain responses in irritable bowel syndrome (see Table 1). The aim of the study was to assess if the drug-reduced/reversed stress-induced hypersensitivity in these patients. The primary outcome defined as 'Signal reductions in the amygdala during viewing of emotional faces and during abdominal pain threat as measured by the fMRI' and a secondary outcome as 'Questionnaires to assess irritable bowel syndrome symptoms and anxiety'. Again the numbers of subjects in the study were relatively few $(n=40$; assumed to represent both patients and controls). The effects of the drug on brain systems in irritable bowel syndrome vs healthy controls have been reported in a recent manuscript: ${ }^{52}$ increased activity in the hypothalamus and locus cerouleus with placebo and decreases in the hypothalamus after the drug that was moderated by anxiety.

Circuitry-based measures of drug efficacy. Ideally, producing a highly effective drug with few or no side effects would be an excellent outcome. Many drugs with good efficacy have side effects that are only detected in later clinical trials. Some CNS diseases are more difficult to get a handle on where there may be diffuse processes (for example, Alzheimer's disease) compared with rapid symptom effects (for example, movement in Parkinson's disease, pain and so on).

Imaging opportunity. In relatively small sample $(n=12-20)$ patients, evaluation of both disease state and drug effects can be performed. Outcomes such as reversal of abnormal circuitry or lack thereof and other specific measures can be evaluated. In addition, comparisons with other drugs or current standards normally require large number of patients. Although subjective measures are helpful, these are notoriously highly variable and subjected to significant biases 
and issues of inter-rater reliability. In addition, filtering out a circuit-based process may contribute to the evaluation of longer-term benefits of the drug. Measures of drug efficacy may be done through either resting state network or evoked stimuli. The advantage of the former is that the patients simply lie in the magnet and do not have to follow any instructions. Therefore, for some CNS diseases where cognitive abilities are altered, this may be a useful approach. As noted in Box 1, resting state networks can differentiate drug effects. Imaging can assess longitudinal changes associated with drug use.

Sample size. Powering clinical studies usually involves large groups of patients because of variability. One of the big issues with clinical trials relates to the nature of the study design and the variability of data acquired, especially in subjective ratings. ${ }^{53-55}$ Clearly diminishing variance allows for a number of benefits including fewer patients required for adequate power of the study and fewer patients are exposed in a drug trial. Both elements have important cost-related benefits. Much of the variance has to do with factors such as inappropriate phenotyping of the population being studied, measurement error, inappropriate end points, problems with responders and non-responders, placebo response, quality of data collected even with good clinical practice standards ${ }^{56}$ including timeline for evaluation of responses. ${ }^{57}$

Imaging opportunity. Imaging data can help decrease the variance within a study population by determining brain changes of drug vs placebo with or without correlations with subjective measures. Such data have come from some studies in healthy subjects in a paradigm evaluating pain using imaging, where activations showed less variance than pain reports. ${ }^{22}$ By implementing novel designs and end points for phase II trials would improve efficiency in defining those New Chemical Entities with potential and quickly eliminating those that have limited efficacy (see Adjei et $a l^{58}$ ). Adding imaging (markers/biomarkers) into this part of the clinical development and specifically defining new end points. The evolution of this type of approach may also help in identifying responders and non-responders at an early stage for methodological considerations in larger phase III trials. New analysis techniques will also allow segregating patients according to subgroups based on their brain nasal states and responses to treatment. ${ }^{59}$

Early comparators: differentiation of new entity with 'Best in Class' or mechanism of action. The placebocontrolled trial has been the standard method to demonstrate efficacy and safety, that is, most CNS clinical trials evaluate New Chemical Entity with a placebo ('A placebo is an inactive pill, liquid, or powder that has no treatment value. In clinical trials, experimental treatments are often compared with placebos to assess the treatment's effectiveness' http:// clinicaltrials.gov). Few CNS trials include an active comparator $\left(\right.$ see Leon ${ }^{60}$ ). So-called 'active-control non-inferiority trials' take this into consideration. ${ }^{61,62}$ phMRI data sets are accruing in a non-defined or non-organized manner (see Table 1), but nevertheless are providing the initial contributions to what could be the development of drug-specific databases that could be used as comparators for new drugs. Many CNS drugs have actions on the CNS that are not well understood.

Imaging opportunity. Data banks on CNS activation of drugs that are now in the non-competitive space can provide a basis for evaluation of new drugs. Thus, the cumulative benefits, particularly if there is the development of a databank, could really help to understand in-vivo drug action in the CNS.

Drugs and clinical relevance: the need for phenotyping and biomarkers. Most drugs are focused on specific targets. Take the antidepressants as an example. The initial appeal of an aminergic target certainly seemed to be valid. Certain aspects clearly questioned the process including the time lag for efficacy. More recently, neural circuit adaptation has been postulated as a process that underlies the potential efficacy of antidepressant drugs. We now have a method to evaluate this. However, and perhaps, equally important is to understand that when we evaluate a drug in a particular population, these patients are of a particular 'phenotype'. This seemingly obvious issue is difficult without the enabling processes afforded by biomarkers. ${ }^{63,64}$ The development of biomarkers for CNS disease would revolutionize the approaches being taken in the drug development domain. Certainly, attempts in different domains are currently at the forefront of many research enterprises across the CNS domain. It is unlikely that many CNS disorders will have a single gene entity that can define the disorder like hemiplegic migraine or erythromelalgia or certain Parkinson's disease subtypes. Thus, other markers are essential to define the clinical phenotype in an objective manner. Accurate phenotyping is critical to any drug trial (see Founti et al. ${ }^{65}$ ). Imaging is one opportunity in the development of biomarkers for drug development. ${ }^{66-68}$

Imaging opportunity. Currently, imaging offers a basis for a 'marker' of drug effect. It has not developed yet to a level of an accepted, regulatory-approved biomarker. Recent advances suggest that imaging may contribute to improving success rates in drug development, but for this to happen, biomarkers need to be defined, validated, reproducible and adopted by regulatory agencies. Figure 4 conceptualizes the use of imaging biomarkers in drug evaluation. The approach may also evolve to have disease fingerprinting ${ }^{69}$ or disease evolution utilizing anatomical measures. ${ }^{70}$ Indeed, the Alzheimer's Disease Neuroimaging Initiative has provided a model for applications of imaging in disease and drug evaluation. ${ }^{71}$

\section{Phase III}

In phase III trials, 'the experimental study drug or treatment is given to large groups of people (1000-3000) to confirm its effectiveness, monitor side effects, compare it to commonly used treatments and collect information that will allow the experimental drug or treatment to be used safely' (http://clinicaltrials.gov). Here tremendous opportunities exist to add imaging information to clinical trial design improve study information. Issues pertaining to predicting natural course of the disease (for example, improvement independent 

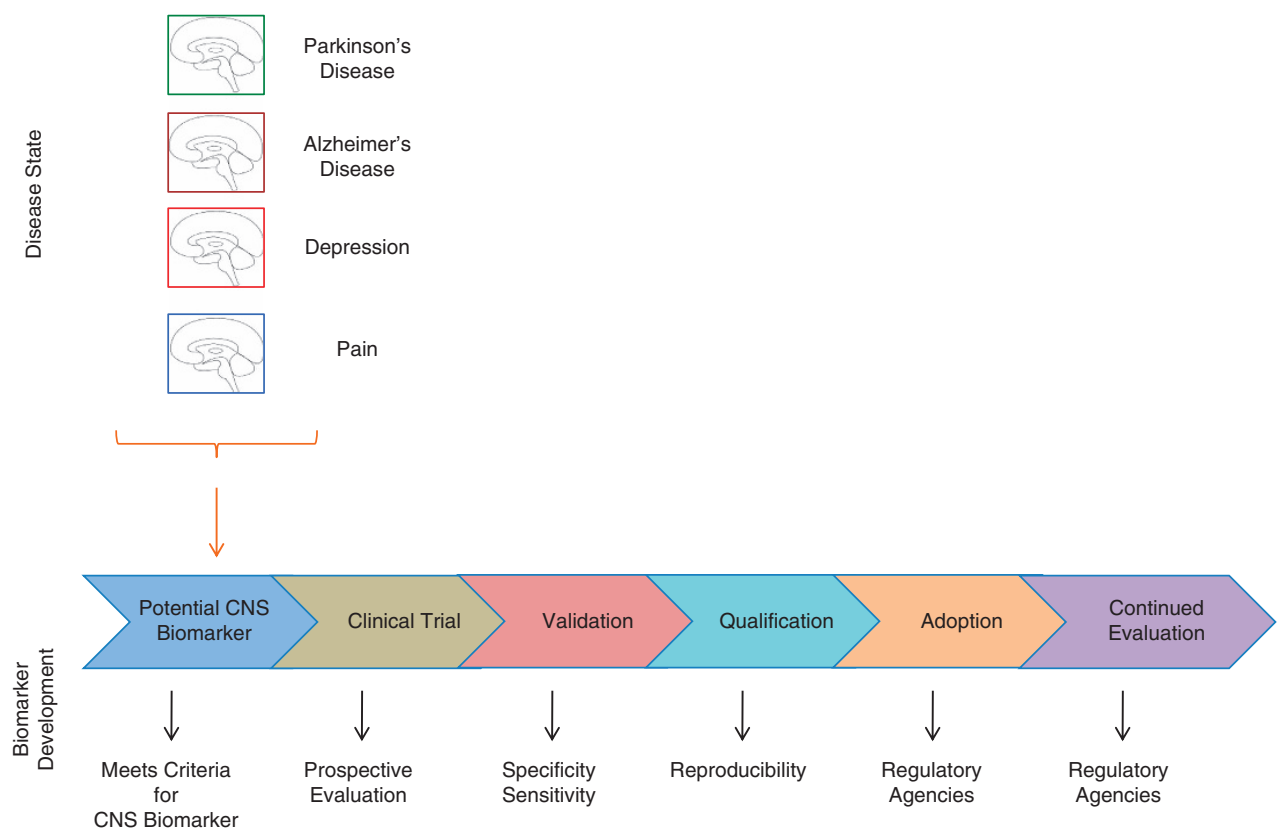

Figure 4 Biomarkers and central nervous system (CNS) drug development (modified from Borsook et al. ${ }^{63}$ ). Imaging biomarkers for specific CNS disease are the focus of a number of research initiatives (Parkinson's disease, ${ }^{131}$ Alzheimer's disease; ${ }^{132}$ depression; ${ }^{133}$ pain ${ }^{63,64}$ ). However, with the exception morphometric imaging in Alzheimer's disease, few have yet to be adopted by regulatory agencies. Nevertheless, the Food and Drug Administration's critical pathway initiative has encouraged the development and use of imaging in drug trials through their Alzheimer's Disease Neuroimaging Initiative program (http://www.adni-info.org). Having validated biomarkers of the disease state (imaging or other) will contribute enormously in clinical trials.

of treatment), predicting responders vs non-responders based on an objective metric can, as in phase II trials, be incorporated into phase III trials. Examples of the use of NMR imaging in phase II include those listed in Table 1; as noted from the table, there are relatively few phase III trials (see section 'Limitations of NMR imaging in drug development: difficulties to overcome as a useful tool in clinical trials' below).

Temporal course of CNS diseases. Symptoms of most CNS diseases fluctuate over time; they are for the most part progressive (for example, Alzheimer's disease) or may be intermittent in severity (for example, depression) or may have a natural course that trends toward improvement (for example, chronic pain or migraine; see Parkinson's Progression Marker Initiative-that involves measures of imaging and other potential makers ${ }^{72}$ ). Thus, understanding if the drug has an effect during the trial or the change is a response to the fluctuation of the disease can critically affect response measures that may have little to do with the drug effect (see Johannsen et al. ${ }^{73}$ ). The issue may be implicated in the failure of clinical trials ${ }^{74}$ because of changes in clinical status (see Kemp et al. ${ }^{75}$ and Geisser et al. ${ }^{76}$ ). Such changes may make the disease more resistant or less resistant, or in some cases may revert to a 'normal' level, as is the case with chronic pain or depression.

Imaging opportunity. Imaging can provide a specific effect of a drug or intervention (Figure 5). For example, the evolving or normalization of a network that may take place as a result of the drug treatment or for other reasons including spontaneous disease remission (for example, in depression).
Ideally, imaging can provide two useful measures: (1) specificity of early markers of drug action and (2) disease state or drug effects over time.

Imaging as an effective measure of drug response. Although placebo-controlled trials have been considered a standard for evaluating a drug, the improved understanding that the placebo effect may be a specific response of a subject based on psychological processes that drive neural systems. ${ }^{77-79}$ Differentiating drug-placebo differences are more difficult in the CNS domain ${ }^{80-82}$ than placebo. As shown in Figure 6, one may classify treated subjects in a CNS clinical trial based on each subject's propensity to respond to a given type of treatment. The D-P-population comprises subjects who are not responsive to both active and inactive treatments. In CNS trials in non-resistant neuropsychiatric disorders, the $D-P$ - group typically represents $50 \%$ of the populations, based on the non-response rates frequently observed with active treatments. Such proportion, naturally, tends to be larger in more resistant populations. The $\mathrm{D}+\mathrm{P}+$ population comprises subjects who are responsive to either active or inactive treatments. In a very large meta-analysis of 182 antidepressant clinical trials pooled $(n=36385)$ from our group, ${ }^{83}$ the average placebo response rate in trials with two active treatments and placebo was about $40 \%$, which is a proxy for the rate of $\mathrm{D}+\mathrm{P}+$ group. When the placebo response (and therefore the $D+P+$ group) is $40 \%$ in a given clinical trial, and the $\mathrm{D}-\mathrm{P}-$ group is $50 \%$, this means that only $10 \%$ of the treated subjects belong to the $\mathrm{D}+\mathrm{P}-$ group, which includes patients who respond to active treatment but not to placebo. Therefore, the higher the placebo rate, the 


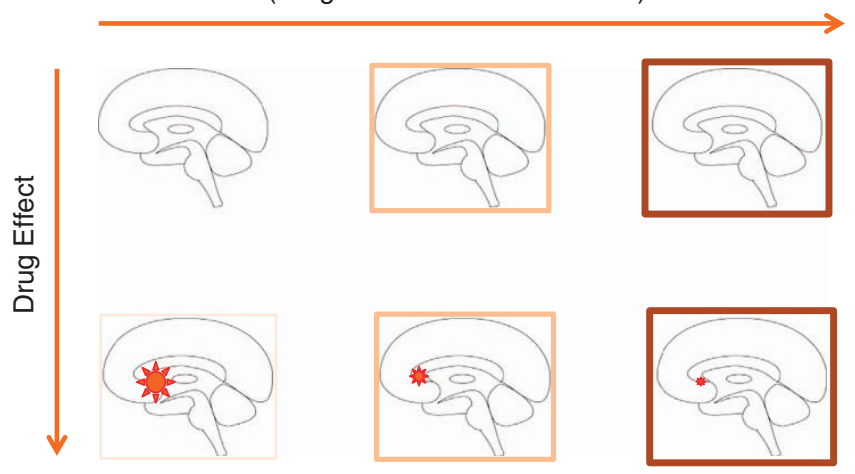

Figure 5 Imaging markers of disease course. Many central nervous system diseases have a progressive and/or undulating course that includes partial or complete remission. A clinical study based on subjective criteria cannot adequately (objectively) evaluate drug effect on disease load (how severe or a relative stage of progression of the disease). These are important factors as for the same dose of a drug (as shown in the lower panels) the effect on brain systems may show diminished efficacy based on disease load. Importantly, such efficacy may be enhanced over time as the drug may have effects over time.

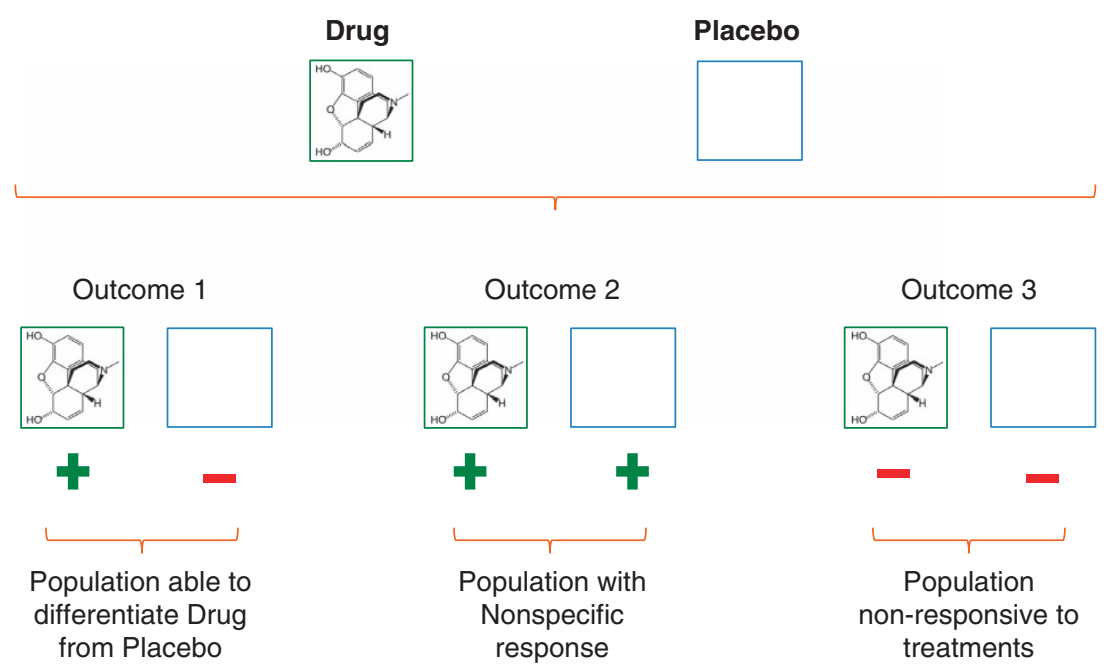

Figure 6 Classification of populations based on propensity to respond to types of treatment (drug $(D)$ or placebo $(P))$. In controlled trials, differentiation of $D$ from $P$ effects can be difficult. Part of the reason for this is that drugs do not provide high degree of efficacy that make this differentiation obvious. As noted above, reasons include three basic outcomes: outcome 1: clear differentiation of D vs P; outcome 2: unclear differentiation of D vs P; and outcome 3: unclear differentiation of lack of efficacy. Taken together, the contribution of outcome 2 in particular, because of lack of effective methods to differentiate $D$ from $P$, can contribute to a false negative result of the trial.

smaller the size of the $\mathrm{D}+\mathrm{P}-$ group, the only informative group of patients. Thus, if the average placebo response rate in antidepressant trials is $40 \%$ or greater, this means that more than $50 \%$ of these adequately powered trials cannot possibly detect a signal, even when the compound is active, as $10 \%$ or less of the sample is informative. How can one improve outcome of category: (1) through differentiation of category, (2) by defining responders to the drug being evaluated vs responders to the placebo. Thus, the issue may be defined in terms of differentiation of responses and responders. These are seemingly straight forward; however, false positive (a good result reported when there actually is not one) and false negative responders (a poor result when there is actually a positive one) complicate the issue. Furthermore, evaluating responders vs non-responders also relates to the heterogeneity of the disease. A major issue related to response is the level of response-is it a complete response (the absence of the symptoms of the disease).
Furthermore, a response may be relatively short lived for various reasons that may include pharmacodynamic, tachyphylaxis and alterations in response because of the course of the disease over time.

Imaging opportunity. Although the placebo (an inactive pill, liquid or powder that has no treatment value (http://clinicaltrials.gov)) would ideally be expected to show no effect because it is an inert substance, the placebo effect can confound results. Differentiation of the placebo effect ('A physical or emotional change, occurring after a substance is taken or administered, that is not the result of any special property of the substance. The change may be beneficial, reflecting the expectations of the participant and, often, the expectations of the person giving the substance' (http://clinicaltrials.gov)) from the drug effect can be problematic. The effect of placebo response rates and how best to measure this in clinical trials has made clinical trials of the 


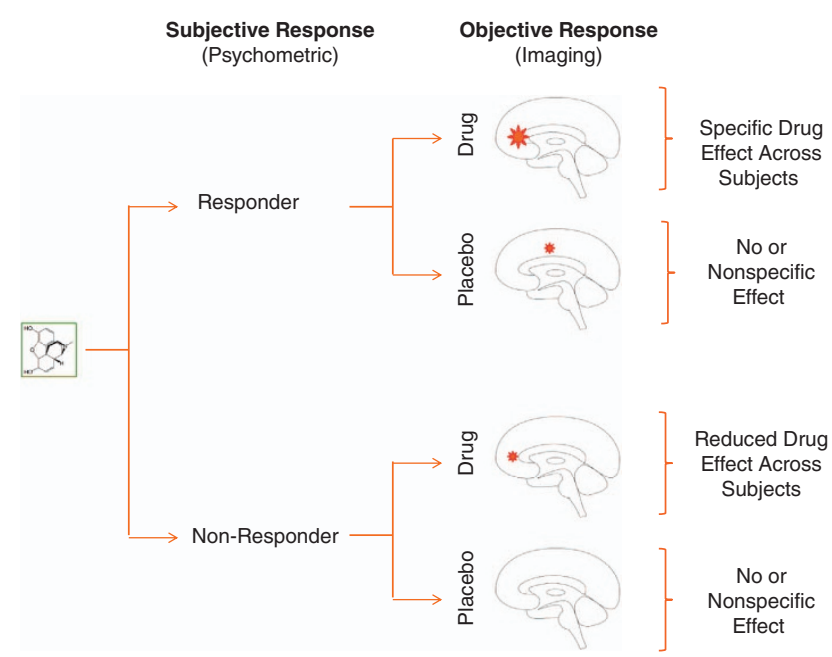

Figure 7 Differentiation of drug effects vs placebo effects with imaging. An imaging readout can define a drug effect or placebo effect. More difficult is a placebo response where drug and the induced placebo response may be similar because similar pathways are involved (for example, in opioids analgesics). However, differences in responders vs non-responders based on integrating subjective and objective (imaging readouts) can help segregate true drug effects from placebo responses. Patients could be segregated into responders and non-responders according to psychometric criteria. Imaging their response to a drug challenge will further allow the determination of specific changes in brain activation and networks as compared with a placebo arm or to non-responders. It will be expected that nonresponders will present a reduced drug effect as well as potential differences in brain networks responses. The inherent difference of responders vs non-responders will also be reflected as difference in brain activity patterns and networks even to a placebo challenge. One of the issues raised in this differentiation is whether drug non-responders are more resistant and thus require increased doses.

CNS a more complex issue. ${ }^{84,85}$ As noted in Figure 7, some patients show clinical improvement in response to the placebo arm of a trial where an inactive compound is used. The variability in placebo response rates in CNS clinical trials may vary. ${ }^{3}$ The large variation makes the trial design challenging because of adequate statistical power and sample size requirements. Furthermore, if patients are not adequately screened or phenotyped, further variation in response to placebo may be observed (for example, between anxious vs non-anxious patients).

Symptom effects vs disease modification. There is no question that the quality of life can be significantly elevated with the control of symptoms. Measures of disease modification that stabilize, limit or reverse or prevent a CNS condition are clearly sought after ${ }^{75,86}$ and are clearly challenges for neuroscience and pharmaceutical industries involved in CNS-related therapies. ${ }^{87}$ To date, however, there are no drugs that completely alleviate disease symptoms (for example, pain, depression and so on). Ideally, treatments that effectively reverse the condition would be a transformational in nature. The problem is that, for the most part, unless some phenomenal genetic or stem cell-type approach emerges, for most pharmacotherapeutics, the process will in all likelihood be slow.

Imaging opportunity. Whatever the disease-modifying treatment approaches are used, stem cell, biologicals and so on, defined measures will be required to evaluate disease modification over time. For some diseases (that is, Alzheimer's) prior work has provided some useful insights into the use of morphometric measures for drug effects on disease outcome (see Cummings ${ }^{88}$ and Weiner et al. ${ }^{89}$ ). Given that most CNS disorders are chronic in nature, brain measures of function and structure can be enormously helpful in measuring progressive changes. In addition, the benefits of multimodal imaging can provide congruent measures on the disease condition or a drug effect. For example, magnetic resonance spectroscopy (see Box 1) can provide a correlate of alterations in gray matter volume changes; gray matter volume changes may correlate with alterations in white matter connectivity that then has implications on functional processing. ${ }^{83,90,91}$

Dosing and drug effectiveness. Once patients are prescribed drugs, they frequently stay on these medications without assessment of how they have altered the brain. Recent data, for example, have questioned the use of some drugs over the long term because of negative effects on brain systems. As such the opportunity to evaluate new approaches to drug therapy, with continued but lower doses, may contribute to equal or even higher efficacy rates in patients for a number of reasons including limiting side effects and thus compliance.

Imaging opportunity. Imaging would provide measures of efficacy in chronic long-term dosing. The issue of long-term medications on the brain (for example, opioids) or long-term consequences of medication (for example, methylphenidate or anesthetics in children) clearly need to be established. Many medications are taken as prescribed for years without evaluation of potential good and bad effects. This is critical as the drug might induce positive changes (that is, tendency or return to 'normal' brain function) or negative ones (for example, migraine chronification from medications including chronic opioids, chronic triptans ${ }^{92,93}$ ).

\section{Implementing integrative imaging in clinical trials}

As noted by Kuhlman' ${ }^{94}$ 'The more thorough and profound studies have been carried out during this exploratory stage of development, the earlier a decision can be made on the continuation or discontinuation of further development. Taking responsibility as the link between research and development gives clinical pharmacology a major opportunity to assume a pivotal role in research and development of new drugs' Drug development has been a sequential process that has included preclinical evaluation (target selection, toxicity profiling for safety and side effects), FIH trials that include drug escalation for maximum tolerated dose (phase I, usually in healthy volunteers), drug efficacy in patients (phase II), efficacy and safety (phase III, with a specific indication usually for regulatory approval) and post-marketing evaluation to determine no unexpected side effects (phase IV). Ideally, the more information that can be collected in early trials predicting outcomes (both good or bad), the more efficient and less costly the process (as information may arise halting the program early or forcing an evaluation that may change the 

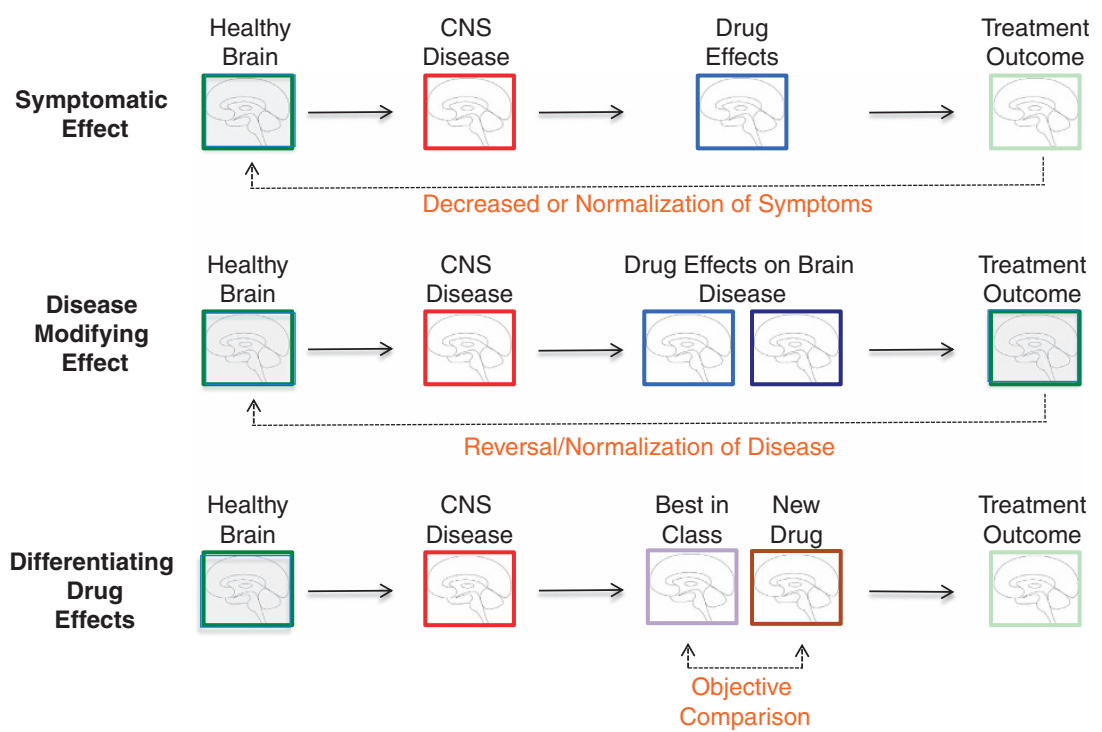

Figure 8 Use of imaging in drug development (adapted from Borsook et al. ${ }^{64}$ ). Imaging can define brain regions involved in symptomatic effects before these become subjectively apparent because of specific circuits activated and their progress to correlative changes with symptoms at a later stage. CNS, central nervous system.

trial or even the indication) (Figure 8). Most trial phases are usually planned and implemented separately, potentially diminishing the benefits of a sequential integrated approach. Transferring useful information including imaging information across development would necessitate an integrated approach to the process. Figure 9 summarizes key points that imaging can bring to the evaluation of a CNS drug candidate in drug development. In other domains of clinical trials, some have supported a role for translational research across the various phases of clinical trials. ${ }^{95}$

\section{Biological considerations}

Comparative studies across drugs and conditions. The FDA has encouraged the use of biomarker approaches to drug development. Hopefully over time, pharmaceutical and biotechnology companies will provide more exciting and useful information on how imaging can help make smart choices in drug development. Through such processes as well as evaluation of drugs in academic centers, an accumulation of a body of knowledge on drug 'fingerprints' on brain systems will allow for a Brain-Drug-Catalogue. The value will be to provide a comparative evaluation of similar drugs (by class or by mechanism of action) in which to compare new drugs. Perhaps this may even become a process that will achieve a consensus to be performed in all phase II studies. Such comparisons could also apply to biosimilar products.

Integrated multimodal imaging approaches. As imaging technologies develop, rapid magnetic resonance sequences can capture a number of brain functional, structural and chemical measures. Integrating such measure can provide further information including response to drugs, predict responders vs non-responders, or early changes in brain systems that may be markers of drug efficacy. More sensitive imaging technologies have already provided novel insights into stroke severity and prediction of outcome, the nature of underlying brain changes in mild traumatic brain injury and so on. Alterations in structure usually accompany changes in function (see Upadhyay et al. ${ }^{32}$ ).

Early evidence of subclinical side effects. Many CNS drugs fail because of side effects. Some brain-defined sideeffects (for example, nausea and vomiting, drowsiness) or unwarranted effects (for example, addition, cognitive changes) can be observed in imaging in small groups of subjects as potential changes would focus attention in early trials and allow for changes to be made in the larger trial design (for example, dosing) or for the drug to stop in its development based on these appraisals. The flip side of this is that unexpected side effects can provide new insights into brain systems and human surrogate models. Perhaps a good example of this is the antimalarial agent mefloquineproducing drug-induced psychosis in otherwise healthy subjects. ${ }^{96,97}$

Clinical trials considerations. A number of issues arise when considering imaging in clinical trials. The first is integration of imaging into trials without confounding regulatory processes and including risks to the trial. If done in a manner that can show enhanced outcomes, this could lead to fewer patients to be exposed to new drugs early in clinical trials (for example, phase II). The second is applying good imaging practice in trials ${ }^{98,99}$ to ensure standards across the industry. As noted in Table 1, there are more clinical trials using imaging, but this is still relatively new and on an 'ad hoc' basis without agreed upon standards and known measures such as sensitivity and specificity (see above). The data listed in the Table 1 are derived from all registered trials from clinicaltrials.gov (http://www.clinicaltrials.gov; see details in section 'Where we are now?' below). The third issue that imaging may evolve into is the validation 

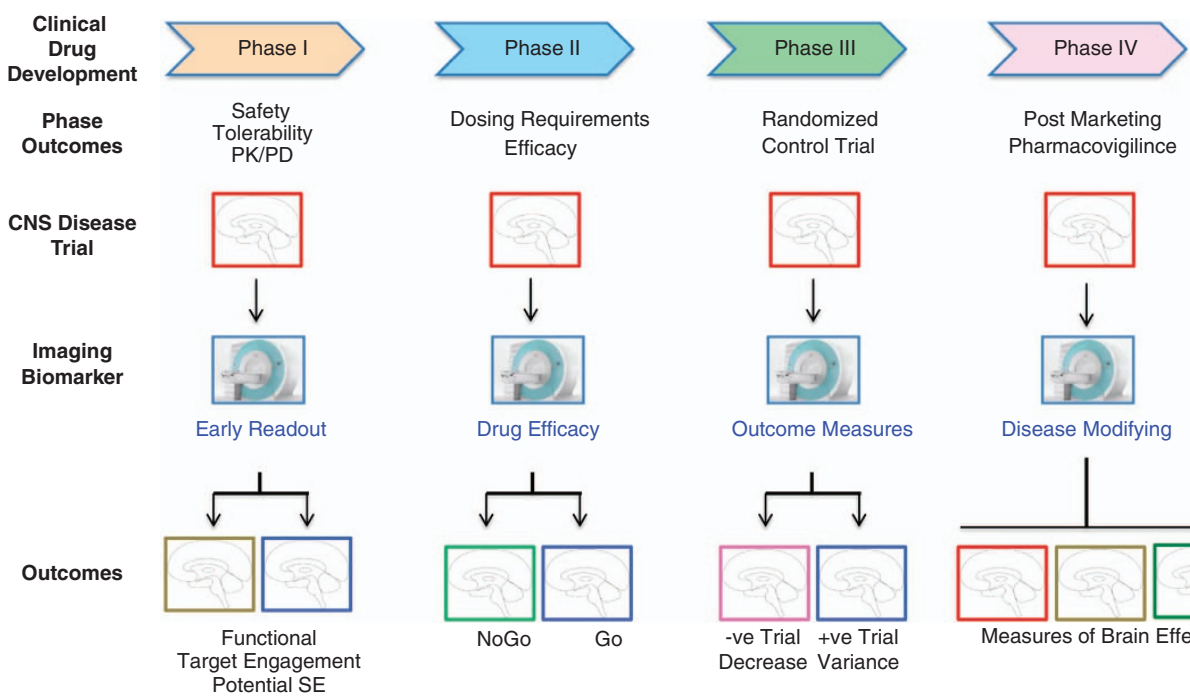

Pharmacovigilince
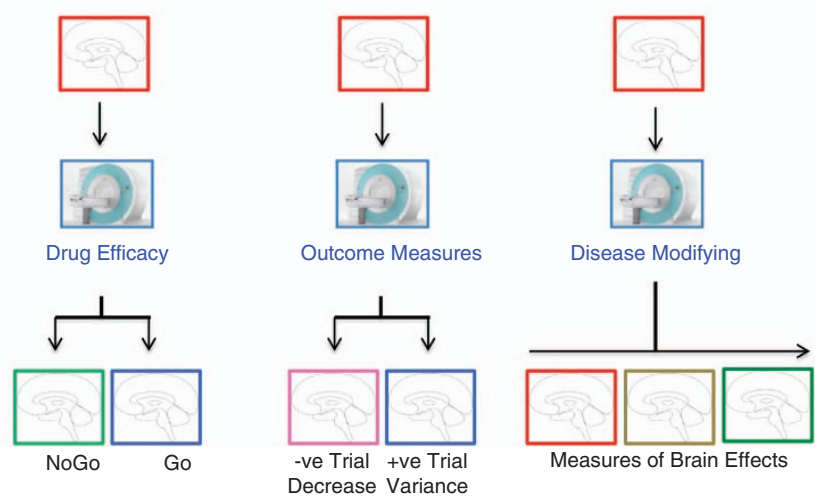

Figure 9 Integrating imaging for central nervous system (CNS)-related clinical trials (modified from Borsook et al..$^{64}$ ). (1) Phase la and imaging—Defining CNS targeting in small groups ( $<12$ subjects); from these studies information on CNS penetration (as evidenced by activation in putative target brain regions); CNS dosing (as determined by correlative measures of plasma PK and CNS effects); and CNS 'target interactions' as determined by brain regions activated by drug (particularly useful if drug is not amenable to positron emission tomography methods) that may be positive (therapeutic) or negative (side effects). (2) Phase II and imaging—Early insights into efficacy and side effects. Specifically, knowledge of how a drug activates circuits postulated to affect disease; early objective measures of responder vs non-responder; combined with subjective measures decreases the variance and thus fewer subjects needed to adequately power the study; and imaging defined markers of potential side effects (for example, drowsiness, addiction potential, nausea and vomiting, cognitive changes and so on); (3) Phase III and Imaging-Responders vs non-responders can further be differentiated. (4) Phase IV and Imaging—Disease modification. PD, pharmacodynamics; PK, pharmacokinetics; SE, side effects.

of surrogate end points. Such information provides a correlate of a clinical end point and is defined as 'a biomarker intended to substitute for a clinical end point' (see Lesko et al. ${ }^{100}$ and Lathia et al. ${ }^{101}$ ).

\section{Financial considerations}

Risk-benefit assessment aided by objective metrics. Decreasing the risk of drug development including the ability to get objective data from relatively small cohorts of individuals, the cost benefits of discontinuing work on drug are critical elements in go-nogo decisions. Obviously, decisions to fund trials are critical to financial success of the drug. However, the risk for investigational drugs is high, especially in the CNS domain where the overall success rates has been around 15\%. ${ }^{102}$ The average cost of a drug from inception/discovery to approval following phase III trials is close to a billion dollars. The costs of drug development from discovery to phase II trials is around $\$ 100$ million. At least three pharmaceutical companies initiated clinical drug development efforts of NK-1 receptor antagonists for a pain indication. The total number of patients evaluated for NK-1 Receptor Antagonist for pain in known investigator-initiated or company-initiated phase II clinical trials is based on available data in the public domain is around 500 individuals (see Borsook et $a .^{38}$ ). If one assumes an investigator (academic, Clinical Research Organization) costs of approximately $\$ 25000-\$ 35000$ per patient, it is around \$12500 000-17500000, notwithstanding, the potential risk for side effects that overall is reported to be relatively minor (for example, diarrhea). These do not take into account a pharmaceutical company's costs; estimates are $\$ 17$ million per year on drugs in phase I, \$34 million on drugs in phase II and \$27 million per year on drugs in phase III of the human clinical trials. ${ }^{103}$ Thus, in the case of the NK-1 receptor antagonists, a conservative estimate of the phase I-II trials across four companies is estimated to cost over $\$ 100$ million. Given the extremely low-side-effect profile of the drug and early preclinical suggestions of alternate indications, the drug has successfully made it into the antiemetic arena, and looks promising in other areas of psychiatric disease. The additional costs for fMRI of a small group of subjects in early phase development (drug has received Investigational New Drug and therefore can be administered to subjects) is around $\$ 1$ million. However, the potential cost-benefits based on the data obtained at this early stage may be enormous (see Borsook et al. ${ }^{38}$ ).

\section{Limitations of NMR imaging in drug development: difficulties to overcome as a useful tool in clinical trials}

Although the potential of imaging across the three phases of clinical trials may be great, enthusiasm should be tempered by current limitations or issues that need to be improved or overcome. Some of these are noted below and in Box 2 .

Technical issues. With all imaging methodologies that measure indirectly brain activity through physiological changes, the underlying issue relates to how much of the change is neural vs physiological. This is especially important in clinical trials in which drug effects are assessed as the drug itself might induce global physiological changes. Although blood oxygenation level dependence is the main approach to perform fMRI experiments, it could be highly affected by drugs altering brain perfusion or reactivity in any 
Box 2 Uses and limitations of NMR imaging

\begin{tabular}{|c|c|}
\hline \multicolumn{2}{|l|}{ Mod } \\
\hline Task/evoked & Specific responses to engaging network \\
\hline Rest & $\begin{array}{l}\text { associated with inputs } \\
\text { Basal brain state potentially } \\
\text { Altered by disease or drug effect }\end{array}$ \\
\hline Reproducibility & $\begin{array}{l}\text { Could be high but varies with condition, across } \\
\text { sites }\end{array}$ \\
\hline Sensitivity & $\begin{array}{l}\text { It varies according to the structure of interest } \\
\text { (size, location), the effect being } \\
\text { measured. }{ }^{119,120}\end{array}$ \\
\hline Specificity & $\begin{array}{l}\text { Higher magnetic field scanners } \\
\text { Allow for higher spatial and temporal } \\
\text { Resolution }\end{array}$ \\
\hline $\mathrm{ARI}$ metrics & Measures neural effects indirectly \\
\hline
\end{tabular}

phMRI activation

Standards

Specificity of neural targets activated

Clinical phenotype Definition of patient phenotype

Need for standards acceptable to industry
Specific responses, but variability may miss effect

Not associated to a particular effect; potentially Identify side-effect profiles

Depends strongly in harmonization of protocols parameters ${ }^{116-118}$

Fairly small structures with weak effects will likely not be detected

Extremely high magnetic field allows sub-millimeter resolution ${ }^{121-123}$

Confounded by systemic hemodynamic effects, but new analytic approaches can account for this.

NMR systems available at most centers

A measure of drug-receptor interactions and down-stream effects; phMRI measures regional and network interactions and may be considered a top-down approach vs bottom-up approach Implementation of standards for drug and disease evaluation $\left(\right.$ see $\left.^{113,114}\right)$ Definition of metrics for signal for a specific brain Many diseases have co-morbidities and these need
example, frequency, low or high states and so on)

Standards for recruitment and classification in trials needs to be improved; this applies to all clinical studies; lack of understanding of pathology of many CNS diseases manner. Several approaches exist to mitigate or quantify physiological effects on blood oxygenation level-dependent signals and include: the recording of physiological parameters (heart rate, blood pressure, end tidal $\mathrm{CO}_{2}$ and so on) to be considered in the analysis, the addition of control scans/experiments of systems that are not affected by the drug and should remain constant (for example, visual system activation) or measure actual physiological changes in brain perfusion such as blood flow measurements with arterial spin labeling. Another technical issues potentially affecting neuroimaging measurements include patient compliance: excessive motion, not following instructions could affect or render useless the acquired data set and without proper monitoring during the scans such data sets can contaminate the overall assessment. However, new imaging analytic approaches including machine vector learning can now be employed to objectively differential subjects, disease subtype and drug effects. ${ }^{104,105}$ Such developments when deployed into the drug trial armamentarium should significantly help further the use of NMR imaging in clinical drug development at the individual and population level. ${ }^{105,106}$

Correlation with disease pathology. We acknowledge that we do not presently have a good understanding of the pathophysiology of the majority of psychiatric disorders. Recently, there has been a change in the field to move from discrete disorders to dimensions and continuous degrees of dysfunction (for example, Research Domain Criteria). Research domain criteria is an approach that aims to define basic dimensions of functioning to be studied across multiple domains of analysis (that is, genes to neural circuits to behaviors). This certainly will impact on the role of imaging in drug development. The correlation of current science and disease with respect to imaging has seen breakthroughs such as markers of disease progression (for example,
Alzheimer's disease) ${ }^{107}$ or regression (for example, chronic pain $)^{108}$ and such brain metrics may correlate with changes in gray matter volume that may correlate with dendritic arborization by disease or stress ${ }^{109,110}$ or drugs; ${ }^{111}$ changes in systems involved in known processes related to the disease (for example, stress and hippocampal changes ${ }^{112}$ ).

Standardization and harmonization. Likely for phase III studies, a multisite approach will be the approach. The use of different scanner manufactures, imaging protocols, could result in an exceeding variance that renders the data unusable. Harmonization of scanner parameters, following validation of imaging sequences across manufacturers, will significantly reduce this problem. The need to define standard methodologies for good imaging practice is essential in order to understand and compare results. A procedural framework for good imaging practice has been suggested. ${ }^{113,114}$ If the applications of NMR measures in clinical drug development are to be implemented, accepted guidelines would need to be adopted. Adoption of such standards will become necessary for imaging to be incorporated into regulatory processes and acceptance by the FDA (http://www.fda.gov) and EMA (http://www.ema.europa.eu). With respect to the latter, issues that will need to be accepted include definition of imaging end points. The issue is not that imaging would usurp clinical end points, but may enhance the process by which clinical end points are reached.

What value would the imaging add to clinical measures? It is not argued that imaging would replace current clinical outcomes, but improve the clinical trial approach by decreasing the risk of the trial to both patients and the drug developers. Right now having an objective diagnosis for many CNS disease states has eluded us, particularly, for psychiatric disease. In the complexity of comorbidity for 
many diseases including neurological disease is a critical issue. For example, in most neurological diseases, comorbid depression is present. ${ }^{115}$ In addition, disease state varies over time, and therefore evaluation of a drug targeted against a specific disease may have a different efficacy profile depending on the 'intransigence' of the disease that relates to its duration and severity. Similar issues may relate to sensitivity of side-effect profiles. Finally, clinical measures of disease modification are difficult to determine and imaging may have a specific niche in this domain. Trials in Alzheimer's disease (refs) and chronic pain (refs) have provided some examples of specific morphometric measures of such changes.

Validity and acceptance. NMR imaging meets some of the Daubert Criteria for use in a legal sense (http://www.law. cornell.edu/wex/daubert_standard) in that it can be tested and therefore validated and the procedure can be peer reviewed. Issues pertaining to the rate of error for NMR imaging in patients or for drug effects is a path forward but that needs to be further evaluated and defined. Although NMR imaging is generally accepted in some of the scientific community, it has not made it to routine clinical use at this time. More stringent measures of sensitivity and specificity will allow for this, and for its potential use in drug development, its acceptance as a method and potentially as a biomarker by regulatory agencies.

\section{Where we are now?}

Table 1 is data collated by searching http://www.clinicaltrials. gov; the search strategy was performed in two phases; the first was for trials listed, a search strategy included 'fMRI', 'phase I' or 'phase II or phase III' and 'drug trial'; the second was a cross check for specific diseases (for example, pain, depression) and for age groups (for example, children). The table provides a number of interesting insights into the use of imaging in evaluating drug effects. As noted in the table, some 70 drugs are represented, suggesting a reasonably active use of $\mathrm{fMRI}$ in drug evaluation, use that has really increased steadily since 2010 .

First, a number of companies are using $\mathrm{fMRI}$ to evaluate novel drugs. Examples are those being developed by Novartis (\#), Glaxo-Smith-Kline (\#24-27, 29), Astra-Zeneca (\#7), EliLilly, ${ }^{29}$ Merck (\#43), Hoffman-LaRoche (\#'s60, 61) and some smaller biotechnology companies (Biotie Therapies Inc., \#67). This does not include other drugs being evaluated for chronic disease at Academic institutions supported by pharmaceutical companies or the $\mathrm{NIH}$. Thus, it would seem that despite ongoing reservations, the use of $\mathrm{FMRI}$, albeit in a limited manner is gaining acceptance across the pharmaceutical industry. Although this adoption may be as an 'add-on' to standard approaches in clinical drug development, more experience and data will provide further insights into the utility of the approach. A recent paper epitomizes ongoing efforts to further understand the utility of imaging in drug development: 'Quantifying the attenuation of the ketamine phMRI response in humans: a validation using antipsychotic and glutamatergic agents $^{124}$ and test-retest reliability to the same drug in healthy subjects. ${ }^{125}$ Thus, through these developments, specific assays for drug evaluation are contributing to greater acceptance in the field.

Second, the use of the technology spans all phases of clinical drug development (see Table 1; phase 1: $n=25$ studies; phase II: $n=11$ studies; phase III: $n=4$ studies; and phase IV: $n=34$ studies). As noted from Table 1, all clinical phase (phase I: $n=25$ studies; phase II: $n=11$ studies; phase III: $n=4$ studies and phase IV: $n=34$ studies). Some studies noted in clinicaltrials.gov are listed with no phase defined and some are listed as combined (that is, I.II). The frequency spread on the use of imaging toward early phase (I) and later phase (IV) may relate to regulatory processes imposed by the FDA or its European equivalent, the EMA. The relative value of use of imaging at different phases is still unclear. Costs of adapting this will probably offset those of ongoing trials that would have either been halted or redirected with insights from functional imaging, the NK-1 receptor antagonist providing a good example. ${ }^{126}$

Third, use of the technology for drugs with different indications (see \#'s 5, 6, 11, 18, 19, 20, 22, 30, 33, 36, 40, 50 and 55) is observed in addition to the use of comparator drugs (for example, 3, 5, 6, 7, 9, 17, 22, 24-26, 423, 54, 55, 60, 64). Notable among these are those that are in pharmaceutical trials. The use of a comparator (either by function or best in class) allows for the evaluation of new insights into a drug being developed. For example, many CNS-acting drug have no clear definition of how they affect brain systems and therefore function in the short and long term. Imaging can define such parameters that may be difficult to ascertain clinically Thus, for example, the evaluation of antidepressants in clinical trials may be helped with the added objective assay in terms of producing a more effective agent.

Fourth, the technology is being used in children and adults. Obviously, many of the major CNS disorders such as attention deficit hyperactivity disorder, autism spectrum disorders, chronic pain (for example, abdominal pain) are conditions that have few effective drugs, and methods to enhance the clinical trial process that includes imaging, may provide useful methods of targeting more effective drugs. This is obviously not an 'an alone state' but dependent on our understanding of neurobiology of disease. The latter has seen advances across many CNS disorders, but clearly this area is still a major confound.

Fifth, for some uses, a model of disease can be defined as exemplified by \#12 and the mefloquine example noted above where a drug produces an abnormal brain state. ${ }^{127,128}$ Imaging can provide a method for assaying circuit function, a basis for behavior. The use of healthy human surrogates in a safe and effective manner to produce reversible alterations in brain function may provide novel insights into disease process, but also models to test drugs without other confounds such as duration of disease, co-morbidities and so on.

Sixth, what is clearly missing from the current state is how best to integrate information from genetic, questionnaire, phenotypic and other criteria currently used to enroll patients into clinical trials. This is clearly an area of opportunity that is being deployed by some groups including ours at Massachusetts General Hospital (Clinical Trials Network and Institute; http://www.massgeneral.org/psychiatry/research/ ctni_home.aspx). 


\section{Conclusions}

We have reached an exciting point in the potential application of NMR technologies in clinical drug development. As the new tool is applied, hurdles will need to be overcome if it is to be accepted into clinical and regulatory programs. There is no doubt that all in the industry would like to see more effective drugs in those areas such as the CNS where a major deficiency currently exists across most brain diseases. Resources have been poured into similar drugs (for example, opioids for pain, anti-depressants and so on) that may not be more efficacious, but have elements of ease of use and fewer side effects. Finally, future uses of 'some complementary techniques (such as arterial spin labeling and magnetoencephalography) that, if used in conjunction with blood oxygenation level-dependent functional MRI, will increase the interpretability and thus the utility of MRI for pharmacology research'. ${ }^{29}$

\section{Conflict of interest}

David Borsook: Research support. Public-Glaxo-Smith Kline; Merck and Company; Eli Lilly; Abbvie; Bristol Myers Squibb; Gruenthal; Vertex; Repligen; Peptimmune; Adolor; Locus; Infinity; National Institute of Neurological Disorders and Stroke; National Center for Complementary and Alternative Medicine (NCCAM); National Institute of Drug Abuse (NIDA). Private-Mayday Fund; Herlands Fund; Childrens Hospital Anesthesia and Radiology Foundations. Advisory/consulting: Merck and Co-Purdue Frederick; Sanofi; Johnson and Johnson; Allergan; Demerx; Dara Pharmaceuticals; Eli Lilly. Speaking/publishing: SpeakingAmerican Society of Clinical Psychopharmacology; Pfizer; Merck and Co; Eli Lilly; Johnson and Johnson; Wyeth; International Association for Pain; International Headache Society. Equity holdings: Stocks-None in public companies; Demerx. Patent-Kirin 5500-licensed to DARA from MGH. Royalty payments: Books-Borsook D, Becerra L, Bullmore E, Hargreaves R, editors. fMRI in CNS Drug Development. Springer 2009. Borsook D, Hargreaves R, Goadsby P, May A. Imaging the Migraine Brain. Oxford University Press. 2012. Copyright: Saving the Child's Brain.

Lino Becerra: Research support: National Institute of General Medical Sciences (NIGMS); National Institute of Neurological Disorders and Stroke (NINDS); National Institutes of Health National Center for Complementary and Alternative Medicine (NCCAM), National Institute of Drug Abuse (NIDA); Glaxo-Smith Kline, Merck and Company. Advisory/Consulting: Pain Research Services,

Massachusetts General Hospital; Medical Imaging Center of Southern California, Santa Monica, CA. Speaking/Publishing: Book-fMRI in CNS Drug Development. Springer 2009. Equity holdings: N/A. Royalty payments: Borsook D, Becerra L, Bullmore E, Hargreaves R, editors. $\mathrm{MRI}$ in CNS Drug Development. Springer 2009.

Maurizio Fava: Research support. Abbot Laboratories; Alkermes, Inc.; Aspect Medical Systems; AstraZeneca; BioResearch; BrainCells Inc.; Bristol-Myers Squibb; CeNeRx BioPharma; Cephalon; Clintara, LLC; Covance; Covidien; Eli Lilly and Company; EIMindA, Ltd.; EnVivo Pharmaceuticals, Inc.; Euthymics Bioscience, Inc.; Forest Pharmaceuticals,
Inc.; Ganeden Biotech, Inc.; GlaxoSmithKline; Harvard Clinical Research Institute; Icon Clinical Research; i3 Innovus/ Ingenix; Janssen R\&D, LLC; Johnson \& Johnson Pharmaceutical Research \& Development; Lichtwer Pharma GmbH; Lorex Pharmaceuticals; MedAvante; National Alliance for Research on Schizophrenia \& Depression (NARSAD); National Center for Complementary and Alternative Medicine (NCCAM); National Institute of Drug Abuse (NIDA); National Institute of Mental Health (NIMH); Neuralstem, Inc.; Novartis AG; Organon Pharmaceuticals; PamLab, LLC.; Pfizer Inc.; Pharmaceutical Research Associates., Inc.; Pharmavite ${ }^{\circledR}$ LLC; PharmoRx Therapeutics; Photothera; Roche Pharmaceuticals; RCT Logic, LLC (formerly Clinical Trials Solutions, LLC); Sanofi-Aventis US LLC; Shire; Solvay Pharmaceuticals, Inc.; Synthelabo; Wyeth-Ayerst Laboratories. Advisory/consulting: Abbott Laboratories; Affectis Pharmaceuticals AG; Alkermes, Inc.; Amarin Pharma Inc.; Aspect Medical Systems; AstraZeneca; Auspex Pharmaceuticals; Bayer AG; Best Practice Project Management, Inc.; BioMarin Pharmaceuticals, Inc.; Biovail Corporation; BrainCells Inc; Bristol-Myers Squibb; CeNeRx BioPharma; Cephalon, Inc.; CNS Response, Inc.; Compellis Pharmaceuticals; Cypress Pharmaceutical, Inc.; DiagnoSearch Life Sciences (P) Ltd.; Dinippon Sumitomo Pharma Co. Inc.; Dov Pharmaceuticals, Inc.; Edgemont Pharmaceuticals, Inc.; Eisai Inc.; Eli Lilly and Company; EnVivo Pharmaceuticals, Inc.; ePharmaSolutions; EPIX Pharmaceuticals, Inc.; Euthymics Bioscience, Inc.; FabreKramer Pharmaceuticals, Inc.; Forest Pharmaceuticals, Inc.; GenOmind, LLC; GlaxoSmithKline; Grunenthal GmbH; i3 Innovus/Ingenis; Janssen Pharmaceutica; Jazz Pharmaceuticals, Inc.; Johnson \& Johnson Pharmaceutical Research \& Development, LLC; Knoll Pharmaceuticals Corp.; Labopharm Inc.; Lorex Pharmaceuticals; Lundbeck Inc.; MedAvante, Inc.; Merck \& Co., Inc.; MSI Methylation Sciences, Inc.; Naurex, Inc.; Neuralstem, Inc.; Neuronetics, Inc.; NextWave Pharmaceuticals; Novartis AG; NuPathe; Nutrition 21; Orexigen Therapeutics, Inc.; Organon Pharmaceuticals; Otsuka Pharmaceuticals; Pamlab, LLC.; Pfizer Inc.; PharmaStar; Pharmavite ${ }^{\circledR}$ LLC.; PharmoRx Therapeutics; Precision Human Biolaboratory; Prexa Pharmaceuticals, Inc.; Puretech Ventures; PsychoGenics; Psylin Neurosciences, Inc.; Rexahn Pharmaceuticals, Inc.; Ridge Diagnostics, Inc.; Roche; Sanofi-Aventis US LLC.; Sepracor Inc.; Servier Laboratories; Schering-Plough Corporation; Solvay Pharmaceuticals, Inc.; Somaxon Pharmaceuticals, Inc.; Somerset Pharmaceuticals, Inc.; Sunovion Pharmaceuticals; Supernus Pharmaceuticals, Inc.; Synthelabo; Takeda Pharmaceutical Company Limited; Tal Medical, Inc.; Tetragenex Pharmaceuticals, Inc.; Teva; TransForm Pharmaceuticals, Inc.; Transcept Pharmaceuticals, Inc.; Vanda Pharmaceuticals, Inc. Speaking/publishing: Adamed, Co; Advanced Meeting Partners; American Psychiatric Association; American Society of Clinical Psychopharmacology; AstraZeneca; Belvoir Media Group; Boehringer Ingelheim $\mathrm{GmbH}$; BristolMyers Squibb; Cephalon, Inc.; CME Institute/Physicians Postgraduate Press, Inc.; Eli Lilly and Company; Forest Pharmaceuticals, Inc.; GlaxoSmithKline; Imedex, LLC; MGH Psychiatry Academy/Primedia; MGH Psychiatry Academy/ 
Reed Elsevier; Novartis AG; Organon Pharmaceuticals; Pfizer Inc.; PharmaStar; United BioSource, Corp.; WyethAyerst Laboratories. Equity holdings: Compellis; PsyBrain, Inc. Royalty/patent, other income: Patent for Sequential Parallel Comparison Design (SPCD), which are licensed by MGH to RCT Logic, LLC; and patent application for a combination of azapirones and bupropion in major depressive disorder (MDD). Copyright for the MGH Cognitive \& Physical Functioning Questionnaire (CPFQ), Sexual Functioning Inventory (SFI), Antidepressant Treatment Response Questionnaire (ATRQ), Discontinuation-Emergent Signs \& Symptoms (DESS), and SAFER; Lippincott, Williams \& Wilkins; Wolkers Kluwer; World Scientific Publishing Co. Pte. Ltd.

Acknowledgements. This study was supported by the Herland's Fund for Pain Research.

1. Drews J. Drug discovery: a historical perspective. Science 2000; 287: 1960-1964

2. Fava M, Rush AJ, Trivedi MH, Nierenberg AA, Thase ME, Sackeim HA et al. Background and rationale for the sequenced treatment alternatives to relieve depression (STAR* $\mathrm{D}$ ) study. Psychiatr Clin North Am 2003; 26: 457-494.

3. Walsh BT, Seidman SN, Sysko R, Gould M. Placebo response in studies of major depression: variable, substantial, and growing. JAMA 2002; 287: 1840-1847.

4. Pangalos MN, Schechter LE, Hurko O. Drug development for CNS disorders: strategies for balancing risk and reducing attrition. Nat Rev Drug Discov 2007; 6: 521-532.

5. Cutler R. Worldwide Clinical Trials 2011 Available from http://www.wwctrials.com.

6. Wong DF, Tauscher J, Grunder G. The role of imaging in proof of concept for CNS drug discovery and development. Neuropsychopharmacology 2009; 34: 187-203.

7. Breivik EK, Bjornsson GA, Skovlund E. A comparison of pain rating scales by sampling from clinical trial data. Clin J Pain 2000; 16: 22-28.

8. Ponce de Leon S, Lara-Munoz C, Feinstein AR, Wells CK. A comparison of three rating scales for measuring subjective phenomena in clinical research. II. Use of experimentally controlled visual stimuli. Arch Med Res 2004; 35: 157-162.

9. Fava M, Evins AE, Dorer DJ, Schoenfeld DA. The problem of the placebo response in clinical trials for psychiatric disorders: culprits, possible remedies, and a novel study design approach. Psychother Psychosom 2003; 72: 115-127.

10. Fava M, Rush AJ, Trivedi MH, Nierenberg AA, Thase ME, Sackeim HA et al. Background and rationale for the sequenced treatment alternatives to relieve depression $\left(\mathrm{STAR}^{*} \mathrm{D}\right)$ study. Psychiatr Clin North Am 2003; 26: 457-494.

11. Chen YF, Yang Y, Hung HM, Wang SJ. Evaluation of performance of some enrichment designs dealing with high placebo response in psychiatric clinical trials. Contemp Clin Trials 2011; 32: 592-604

12. Fava M, Mischoulon D, losifescu D, Witte J, Pencina M, Flynn M et al. A double-blind, placebo-controlled study of aripiprazole adjunctive to antidepressant therapy among depressed outpatients with inadequate response to prior antidepressant therapy (ADAPT-A Study). Psychother Psychosomatics 2012; 81: 87-97.

13. Papakostas Gl, Shelton RC, Zajecka JM, Etemad B, Rickels K, Clain A et al. L-methylfolate as adjunctive therapy for SSRI-resistant major depression: results of two randomized, double-blind, parallel-sequential trials. Am J Psychiatry 2012; 169 : 1267-1274

14. Amin DV, Doctor RB, Girdhar AO, Shah UH. The effect of beta-adrenergic stimulation and blockade on the efflux of PGE1-like material from the isolated perfused rabbit heart. Experientia 1980; 36: 1410-1411

15. van Wingen GA, Zylicz SA, Pieters S, Mattern C, Verkes RJ, Buitelaar JK et al. Testosterone increases amygdala reactivity in middle-aged women to a young adulthood level. Neuropsychopharmacology 2009; 34: 539-547.

16. Kraft E, Loichinger W, Diepers M, Lule D, Schwarz J, Ludolph AC et al. Levodopainduced striatal activation in Parkinson's disease: a functional MRI study. Parkinsonism Relat Disord 2009; 15: 558-563.

17. Pontari MA, Mohamed FB, Lebovitch S, Moonat S, Lebed B, Ruggieri MR et al. Central nervous system findings on functional magnetic resonance imaging in patients before and after treatment with anticholinergic medication. J Urol 2010; 183: 1899-1905.

18. Lui S, Li T, Deng W, Jiang L, Wu Q, Tang $\mathrm{H}$ et al. Short-term effects of antipsychotic treatment on cerebral function in drug-naive first-episode schizophrenia revealed by 'resting state' functional magnetic resonance imaging. Arch Gen Psychiatry 2010; 67 783-792

19. Diers M, Yilmaz P, Rance M, Thieme K, Gracely RH, Rolko C et al. Treatment-related changes in brain activation in patients with fibromyalgia syndrome. Exp Brain Res 2012 218: 619-628.
20. Bell EC, Willson MC, Wilman AH, Dave S. Silverstone PH. Differential effects of chronic lithium and valproate on brain activation in healthy volunteers. Hum Psychopharmacol 2005; 20: 415-424.

21. Borsook D, Pendse G, Aiello-Lammens M, Glicksman M, Gostic J, Sherman S et al. CNS response to a thermal stressor in human volunteers and awake rats may predict clinical utility of analgesics. Drug Dev Res 2007; 68: 23-41.

22. Upadhyay J, Anderson J, Schwarz AJ, Coimbra A, Baumgartner R, Pendse G et al. Imaging drugs with and without clinical analgesic efficacy. Neuropsychopharmacology 2011; 36: 2659-2673.

23. Upadhyay J, Anderson J, Baumgartner R, Coimbra A, Schwarz AJ, Pendse G et al. Modulation of CNS pain circuitry by intravenous and sublingual doses of buprenorphine. Neurolmage 2012; 59: 3762-3773.

24. Damoiseaux JS, Rombouts SA, Barkhof F, Scheltens P, Stam CJ, Smith SM et al. Consistent resting-state networks across healthy subjects. Proc Natl Acad Sci USA 2006; 103: 13848-13853.

25. Boveroux P, Vanhaudenhuyse A, Bruno MA, Noirhomme Q, Lauwick S, Luxen A et al. Breakdown of within- and between-network resting state functional magnetic resonance imaging connectivity during propofol-induced loss of consciousness. Anesthesiology 2010; 113: 1038-1053.

26. Tanabe J, Nyberg E, Martin LF, Martin J, Cordes D, Kronberg E et al. Nicotine effects on default mode network during resting state. Psychopharmacology (Berl) 2011; 216: 287-295.

27. Khalili-Mahani N, Zoethout RM, Beckmann CF, Baerends E, de Kam ML, Soeter RP et al. Effects of morphine and alcohol on functional brain connectivity during 'resting state': a placebo-controlled crossover study in healthy young men. Hum Brain Mapp 2012; 33: 1003-1018.

28. Newhouse PA, Potter AS, Dumas JA, Thiel CM. Functional brain imaging of nicotinic effects on higher cognitive processes. Biochem Pharmacol 2011; 82: 943-951.

29. Jenkins BG. Pharmacologic magnetic resonance imaging (phMRI): imaging drug action in the brain. Neuroimage 2012; 62: 1072-1085

30. Detre JA, Rao H, Wang DJ, Chen YF, Wang Z. Applications of arterial spin labeled MRI in the brain. J Magn Reson Imaging 2012; 35: 1026-1037.

31. Yuksel C, McCarthy J, Shinn A, Pfaff DL, Baker JT, Heckers $S$ et al. Gray matter volume in schizophrenia and bipolar disorder with psychotic features. Schizophr Res 2012; 138: 177-182.

32. Upadhyay J, Maleki N, Potter J, Elman I, Rudrauf D, Knudsen J et al. Alterations in brain structure and functional connectivity in prescription opioid-dependent patients. Brain 2010; 133(Pt 7): 2098-2114.

33. Liao $\mathrm{Y}$, Tang J, Ma M, Wu Z, Yang M, Wang $\mathrm{X}$ et al. Frontal white matter abnormalities following chronic ketamine use: a diffusion tensor imaging study. Brain 2010; 133(Pt 7): 2115-2122.

34. Harris RE, Sundgren PC, Pang Y, Hsu M, Petrou M, Kim SH et al. Dynamic levels of glutamate within the insula are associated with improvements in multiple pain domains in fibromyalgia. Arthritis Rheum 2008; 58: 903-907.

35. Tibbitts J, Cavagnaro JA, Haller CA, Marafino B, Andrews PA, Sullivan JT. Practical approaches to dose selection for first-in-human clinical trials with novel biopharmaceuticals. Regul Toxicol Pharmacol 2010; 58: 243-251.

36. Dresser R. First-in-human trial participants: not a vulnerable population, but vulnerable nonetheless. J Law Med Ethics 2009 Spring; 37: 38-50.

37. Potschka H. Targeting the brain-surmounting or bypassing the blood-brain barrier. Handb Exp Pharmacol 2010; 197: 411-431.

38. Borsook D, Upadhyay J, Klimas M, Schwarz A, Coimbra A, Baumgartner R et al. Decision-making using fMRI in clinical drug development: revisiting the NK-1 receptor antagonist for pain. Drug Discov Today 2012; 17: 964-973.

39. Upadhyay J, Anderson J, Schwarz AJ, Coimbra A, Baumgartner R, Pendse G et al. Imaging drugs with and without clinical analgesic efficacy. Neuropsychopharmacology 2011; 36: 2659-2673.

40. McKie S, Richardson P, Elliott R, Vollm BA, Dolan MC, Williams SR et al. Mirtazapine antagonises the subjective, hormonal and neuronal effects of $m$-chlorophenylpiperazine (mCPP) infusion: a pharmacological-challenge fMRI (phMRI) study. Neuroimage 2011; 58: 497-507.

41. Gear R, Becerra L, Upadhyay J, Bishop J, Wallin D, Pendse G et al. Pain facilitation brain regions activated by nalbuphine are revealed by pharmacological FMRI. PLoS One 2013; 8: e50169.

42. Buoen C, Bjerrum OJ, Thomsen MS. How first-time-in-human studies are being performed: a survey of phase I dose-escalation trials in healthy volunteers published between 1995 and 2004. J Clin Pharmacol 2005; 45: 1123-1136.

43. Damoiseaux JS. Resting-state fMRI as a biomarker for Alzheimer's disease? Alzheimers Res Ther 2012; 4: 8

44. Poston KL, Tang CC, Eckert T, Dhawan V, Frucht S, Vonsattel JP et al. Network correlates of disease severity in multiple system atrophy. Neurology 2012; 78: 1237-1244.

45. Musen G, Jacobson AM, Bolo NR, Simonson DC, Shenton ME, McCartney RL et al. Resting-state brain functional connectivity is altered in type 2 diabetes. Diabetes 2012; 61: 2375-2379.

46. Farbota KD, Bendlin BB, Alexander AL, Rowley HA, Dempsey RJ, Johnson SC. Longitudinal diffusion tensor imaging and neuropsychological correlates in traumatic brain injury patients. Front Hum Neurosci 2012; 6: 160. 
47. Brier MR, Thomas JB, Snyder AZ, Benzinger TL, Zhang D, Raichle ME et al. Loss of intranetwork and internetwork resting state functional connections with Alzheimer's disease progression. J Neurosci 2012; 32: 8890-8899.

48. Baliki MN, Petre B, Torbey S, Herrmann KM, Huang L, Schnitzer TJ et al. Corticostriatal functional connectivity predicts transition to chronic back pain. Nat Neurosci 2012; 15 : 1117-1119.

49. Zhou SY, Shu C, Korth-Bradley J, Raible D, Palmisano M, Wadjula J et al. Integrated population pharmacokinetics of etanercept in healthy subjects and in patients with rheumatoid arthritis and ankylosing spondylitis. J Clin Pharmacol 2011; 51: 864-875.

50. Cutler NR, Sramek JJ. Exploratory studies: implications for drug development in Alzheimer's disease. Rev Neurol (Paris) 1998; 154(Suppl 2): S131-S136.

51. Targum SD, Pollack MH, Fava M. Redefining affective disorders: relevance for drug development. CNS Neurosci Ther 2008 Spring 14: 2-9.

52. Hubbard CS, Labus JS, Bueller J, Stains J, Suyenobu B, Dukes GE et al. Corticotropinreleasing factor receptor 1 antagonist alters regional activation and effective connectivity in an emotional-arousal circuit during expectation of abdominal pain. J Neurosci $2011 ; 31$ : 12491-12500.

53. Jensen K, Kieser M. Blinded sample size recalculation in multicentre trials with normally distributed outcome. Biom J 2010; 52: 377-399.

54. Ridenour TA, Hall DL, Bost JE. A small sample randomized clinical trial methodology using N-of-1 designs and mixed model analysis. Am J Drug Alcohol Abuse 2009; 35: 260-266.

55. Perlstein I, Bolognese JA, Krishna R, Wagner JA. Evaluation of agile designs in first-in-human (FIH) trials-a simulation study. Aaps J 2009; 11: 653-663.

56. Nahm ML, Pieper CF, Cunningham MM. Quantifying data quality for clinical trials using electronic data capture. PLoS One 2008; 3: e3049.

57. Tedeschini E, Fava M, Papakostas Gl. Placebo-controlled, antidepressant clinical trials cannot be shortened to less than 4 weeks' duration: a pooled analysis of randomized clinical trials employing a diagnostic odds ratio-based approach. J Clin Psychiatry 2011; 72: 98-118.

58. Adjei AA, Christian M, Ivy P. Novel designs and end points for phase II clinical trials. Clin Cancer Res 2009; 15: 1866-1872.

59. Yang Z, Zuo XN, Wang P, Li Z, LaConte SM, Bandettini PA et al. Generalized RAICAR: discover homogeneous subject (sub)groups by reproducibility of their intrinsic connectivity networks. Neurolmage 2012; 63: 403-414.

60. Leon AC. Comparative effectiveness clinical trials in psychiatry: superiority, noninferiority, and the role of active comparators. J Clin Psychiatry 2011; 72: 1344-1349.

61. Fleischhacker WW, Czobor P, Hummer M, Kemmler G, Kohnen R, Volavka J. Placebo or active control trials of antipsychotic drugs? Arch Gen Psychiatry 2003; 60: 458-464.

62. Le Henanff A, Giraudeau B, Baron G, Ravaud P. Quality of reporting of noninferiority and equivalence randomized trials. JAMA 2006; 295: 1147-1151.

63. Borsook D, Becerra L, Hargreaves R. Biomarkers for chronic pain and analgesia. Part 1: the need, reality, challenges, and solutions. Discov Med 2011; 11: 197-207.

64. Borsook D, Becerra L, Hargreaves R. Biomarkers for chronic pain and analgesia. Part 2: how, where, and what to look for using functional imaging. Discov Med 2011; 11: 209-219.

65. Founti P, Topouzis F, van Koolwijk L, Traverso CE, Pfeiffer N, Viswanathan AC. Biobanks and the importance of detailed phenotyping: a case study-the European Glaucoma Society GlaucoGENE project. Br J Ophthalmol 2009; 93: 577-581.

66. Wong DF, Grunder G, Brasic JR. Brain imaging research: does the science serve clinical practice? Int Rev Psychiatry 2007; 19: 541-558.

67. Wiedemann K. Biomarkers in development of psychotropic drugs. Dialogues Clin Neurosci 2011; 13: 225-234.

68. Hampel H, Prvulovic D, Teipel SJ, Bokde AL. Recent developments of functional magnetic resonance imaging research for drug development in Alzheimer's disease. Prog Neurobiol 2011; 95: 570-578.

69. Mattila J, Koikkalainen J, Virkki A, Simonsen A, van Gils M, Waldemar G et al. A disease state fingerprint for evaluation of Alzheimer's disease. J Alzheimer's Dis 2011; 27: 163-176.

70. Risacher SL, Shen L, West JD, Kim S, McDonald BC, Beckett LA et al. Longitudinal MR atrophy biomarkers: relationship to conversion in the ADNI cohort. Neurobiol Aging 2010; 31: $1401-1418$

71. Weiner MW, Veitch DP, Aisen PS, Beckett LA, Cairns NJ, Green RC et al. The Alzheimer's disease neuroimaging initiative: a review of papers published since its inception. Alzheimer's Demen 2012; 8(1 Suppl): S1-68.

72. Marek K, Jennings D, Lasch S, Siderowf A, Tanner $C$ et al. The Parkinson Progression Marker Initiative (PPMI). Prog Neurobiol 2011; 95: 629-635.

73. Johannsen P, Salmon E, Hampel H, Xu Y, Richardson S, Qvitzau S et al. Assessing therapeutic efficacy in a progressive disease: a study of donepezil in Alzheimer's disease. CNS Drugs 2006; 20: 311-325.

74. Dolgin E. Fluctuating baseline pain implicated in failure of clinical trials. Nat Med 2010; 16: 1053.

75. Kemp AS, Grossberg GT, Romano SJ, Arnold DL, Ryan JM, Bullock R et al. Trial designs likely to meet valid long-term Alzheimer's disease progression effects: learning from the past, preparing for the future. Int J Alzheimers Dis 2009; 2009: 949271.

76. Geisser ME, Clauw DJ, Strand V, Gendreau RM, Palmer R, Williams DA. Contributions of change in clinical status parameters to Patient Global Impression of Change
(PGIC) scores among persons with fibromyalgia treated with milnacipran. Pain 2010; 149: 373-378.

77. Oeltjenbruns J, Schafer M. [Clinical significance of the placebo effect]. Anaesthesist 2008; 57: 447-463.

78. Pollo A, Benedetti $F$. The placebo response: neurobiological and clinical issues of neurological relevance. Prog Brain Res 2009; 175: 283-294.

79. Benedetti F, Carlino E, Pollo A. How placebos change the patient's brain. Neuropsychopharmacology 2011; 36: 339-354.

80. Dworkin RH, Katz J, Gitlin MJ. Placebo response in clinical trials of depression and its implications for research on chronic neuropathic pain. Neurology 2005; 65(12 Suppl 4): S7-S19.

81. Cutler NR, Sramek JJ, Murphy MF, Riordan H, Biek P, Carta A. Critical Pathways to Success in CNS Drug Development 1 edn 2010.

82. Kemp AS, Schooler NR, Kalali AH, Alphs L, Anand R, Awad G et al. What is causing the reduced drug-placebo difference in recent schizophrenia clinical trials and what can be done about it? Schizophr Bull 2010; 36: 504-509.

83. Papakostas GI, Fava M. Does the probability of receiving placebo influence clinical trial outcome? A meta-regression of double-blind, randomized clinical trials in MDD. Eur Neuropsychopharmacol 2009; 19: 34-40.

84. Sinyor M, Levitt AJ, Cheung AH, Schaffer A, Kiss A, Dowlati Y et al. Does inclusion of a placebo arm influence response to active antidepressant treatment in randomized controlled trials? Results from pooled and meta-analyses. J Clin Psychiatry 2010; 71 270-279.

85. Hughes J, Gabbay M, Funnell E, Dowrick C. Exploratory review of placebo characteristics reported in randomised placebo controlled antidepressant drug trials. Pharmacopsychiatry 2012; 45: 20-27

86. Goodin DS, Frohman EM, Garmany GP Jr., Halper J, Likosky WH, Lublin FD et al. Disease modifying therapies in multiple sclerosis: report of the Therapeutics and Technology Assessment Subcommittee of the American Academy of Neurology and the MS Council for Clinical Practice Guidelines. Neurology 2002; 58: 169-178.

87. Lang AE. Clinical trials of disease-modifying therapies for neurodegenerative diseases: the challenges and the future. Nat Med 2010; 16: 1223-1226.

88. Cummings $\mathrm{JL}$. Integrating ADNI results into Alzheimer's disease drug development programs. Neurobiol Aging 2010; 31: 1481-1492.

89. Weiner MW, Veitch DP, Aisen PS, Beckett LA, Cairns NJ, Green RC et al. The Alzheimer's disease neuroimaging initiative: a review of papers published since its inception. Alzheimer's Dement 2012; 8(1 Suppl): S1-68.

90. O'Muircheartaigh J, Vollmar C, Barker GJ, Kumari V, Symms MR, Thompson P et al. Abnormal thalamocortical structural and functional connectivity in juvenile myoclonic epilepsy. Brain 2012; 135(Pt 12): 3635-3644.

91. Amad A, Cachia A, Gorwood P, Pins D, Delmaire C, Rolland B et al. The multimodal connectivity of the hippocampal complex in auditory and visual hallucinations. Mol Psychiatry 2013; PubMed PMID: 23318999, volume 24; pp 483-490.

92. Bigal ME, Rapoport AM, Sheftell FD, Tepper SJ, Lipton RB. Transformed migraine and medication overuse in a tertiary headache centre-clinical characteristics and treatment outcomes. Cephalalgia 2004; 24: 483-490.

93. Bigal ME, Lipton RB. Overuse of acute migraine medications and migraine chronification. Curr Pain Headache Rep 2009; 13: 301-307.

94. Kuhlmann J. Alternative strategies in drug development: clinical pharmacological aspects. Int J Clin Pharmacol Ther 1999; 37: 575-583.

95. Lonning PE. Strength and weakness of phase I to IV trials, with an emphasis on translational aspects. Breast Cancer Res 2008; 10(Suppl 4): S22.

96. Toovey S. Mefloquine neurotoxicity: a literature review. Travel Med Infect Dis 2009; 7: 2-6.

97. Nevin RL. Mefloquine prescriptions in the presence of contraindications: prevalence among US military personnel deployed to Afghanistan, 2007. Pharmacoepidemiol Drug Saf 2010; 19: 206-210.

98. Schwarz AJ, Becerra L, Upadhyay J, Anderson J, Baumgartner R, Coimbra A et al. A procedural framework for good imaging practice in pharmacological fMRI studies applied to drug development \#1: processes and requirements. Drug Discov Today 2011; 16: 583-593.

99. Schwarz AJ, Becerra L, Upadhyay J, Anderson J, Baumgartner R, Coimbra A et al. A procedural framework for good imaging practice in pharmacological fMRI studies applied to drug development \#2: protocol optimization and best practices. Drug Discov Today 2011; 16: 671-682.

100. Lesko LJ, Atkinson AJ Jr. Use of biomarkers and surrogate endpoints in drug development and regulatory decision making: criteria, validation, strategies. Annu Rev Pharmacol Toxicol 2001; 41: 347-366.

101. Lathia CD. Biomarkers and surrogate endpoints: how and when might they impact drug development? Dis Markers 2002; 18: 83-90.

102. Dimasi JA. Risks in new drug development: approval success rates for investigational drugs. Clin Pharmacol Ther 2001; 69: 297-307.

103. Adams CP, Brantner VV. Spending on new drug development1. Health Econ 2010; 19: 130-141.

104. O'Dwyer L, Lamberton F, Bokde AL, Ewers M, Faluyi YO, Tanner C et al. Using support vector machines with multiple indices of diffusion for automated classification of mild cognitive impairment. PLoS One 2012; 7: e32441.

105. Haller S, Nguyen D, Rodriguez C, Emch J, Gold G, Bartsch A et al. Individual prediction of cognitive decline in mild cognitive impairment using support vector 
machine-based analysis of diffusion tensor imaging data. J Alzheimer's Dis, 2010; 22 315-327.

106. Grosenick L, Klingenberg B, Katovich K, Knutson B, Taylor JE. Interpretable whole-brain prediction analysis with GraphNet. Neurolmage 2013; 72: 304-321.

107. Douaud G, Menke RA, Gass A, Monsch AU, Rao A, Whitcher B et al. Brain microstructure reveals early abnormalities more than two years prior to clinical progression from mild cognitive impairment to Alzheimer's disease. J Neurosci 2013; 33: 2147-2155.

108. Seminowicz DA, Wideman TH, Naso L, Hatami-Khoroushahi Z, Fallatah S, Ware MA et al. Effective treatment of chronic low back pain in humans reverses abnormal brain anatomy and function. J Neurosci 2011; 31: 7540-7550.

109. Metz AE, Yau HJ, Centeno MV, Apkarian AV, Martina M. Morphological and functional reorganization of rat medial prefrontal cortex in neuropathic pain. Proc Natl Acad Sci USA 2009; 106: 2423-2428.

110. Radley JJ, Sisti HM, Hao J, Rocher AB, McCall T, Hof PR et al. Chronic behavioral stress induces apical dendritic reorganization in pyramidal neurons of the medial prefrontal cortex. Neuroscience 2004; 125: 1-6.

111. Robinson TE, Kolb B. Structural plasticity associated with exposure to drugs of abuse. Neuropharmacology 2004; 47(Suppl 1): 33-46.

112. Oliveira JF, Dias NS, Correia M, Gama-Pereira F, Sardinha VM, Lima A et al. Chronic stress disrupts neural coherence between cortico-limbic structures. Front Neural Circuits 2013; $7: 10$.

113. Schwarz AJ, Becerra L, Upadhyay J, Anderson J, Baumgartner R, Coimbra A et al. A procedural framework for good imaging practice in pharmacological fMRI studies applied to drug development \#1: processes and requirements. Drug Discov Today 2011; 16: 583-593.

114. Schwarz AJ, Becerra L, Upadhyay J, Anderson J, Baumgartner R, Coimbra A et al. A procedural framework for good imaging practice in pharmacological fMRI studies applied to drug development \#2: protocol optimization and best practices. Drug Discov Today 2011; 16: 671-682.

115. Borsook D. Neurological diseases and pain. Brain 2012; 135(Pt 2): 320-344

116. Gountouna VE, Job DE, McIntosh AM, Moorhead TW, Lymer GK, Whalley HC et al. Functional Magnetic Resonance Imaging (fMRI) reproducibility and variance components across visits and scanning sites with a finger tapping task. Neurolmage 2010; 49: $552-560$.

117. Zou KH, Greve DN, Wang M, Pieper SD, Warfield SK, White NS et al. Reproducibility of functional MR imaging: preliminary results of prospective multi-institutional study performed by Biomedical Informatics Research Network. Radiology 2005; 237 781-789.

118. Loubinoux I, Carel C, Alary F, Boulanouar K, Viallard G, Manelfe C et al. Within-session and between-session reproducibility of cerebral sensorimotor activation: a test-retest effect evidenced with functional magnetic resonance imaging. J Cerebral Blood Flow Metab 2001; 21: 592-607.

119. Thirion B, Pinel P, Meriaux S, Roche A, Dehaene S, Poline JB. Analysis of a large fMRI cohort: Statistical and methodological issues for group analyses. Neurolmage 2007; 35: 105-120.
120. Thirion B, Pinel P, Tucholka A, Roche A, Ciuciu P, Mangin JF et al. Structural analysis of fMRI data revisited: improving the sensitivity and reliability of $\mathrm{AMRI}$ group studies. IEEE Trans Med Imaging 2007; 26: 1256-1269.

121. Olman CA, Yacoub E. High-field FMRI for human applications: an overview of spatial resolution and signal specificity. Open Neuroimaging J 2011; 5: 74-89.

122. Chen W, Ugurbil K. High spatial resolution functional magnetic resonance imaging at very-high-magnetic field. Top Magn Resonan Imaging 1999; 10: 63-78.

123. Yacoub E, Harel N, Ugurbil K. High-field fMRI unveils orientation columns in humans. Proc Natl Acad Sci USA 2008; 105: 10607-10612.

124. Doyle OM, De Simoni S, Schwarz AJ, Brittain C, O'Daly OG, Williams SC et al. Quantifying the attenuation of the ketamine phMRI response in humans: a validation using antipsychotic and glutamatergic agents. J Pharmacol Exper Ther 2013; 345: 151-160.

125. De Simoni S, Schwarz AJ, O'Daly OG, Marquand AF, Brittain C, Gonzales C et al. Testretest reliability of the BOLD pharmacological MRI response to ketamine in healthy volunteers. Neurolmage 2013; 64: 75-90.

126. Borsook D, Upadhyay J, Klimas M, Schwarz AJ, Coimbra A, Baumgartner R et al. Decision-making using fMRI in clinical drug development: revisiting NK-1 receptor antagonists for pain. Drug Discov Today 2012; 17: 964-973.

127. van Riemsdijk MM, Sturkenboom MC, Pepplinkhuizen L, Stricker BH. Mefloquine increases the risk of serious psychiatric events during travel abroad: a nationwide casecontrol study in the Netherlands. J Clin Psychiatry 2005; 66: 199-204.

128. Toovey S. Mefloquine neurotoxicity: a literature review. Travel Med Infect Dis 2009; 7: $2-6$

129. Murphy SE, Mackay CE. Using MRI to measure drug action: caveats and new directions. J Psychopharmacol 2011; 25: 1168-1174.

130. Becerra L, Schwartzman RJ, Kiefer RT, Rohr P, Moulton EA, Wallin D et al. CNS measures of pain responses pre- and post-anesthetic ketamine in a patient with complex regional pain syndrome. Pain Med 2009 PubMed PMID: 19254342. Epub 2009/03/04. Eng.

131. Brooks DJ, Pavese N. Imaging biomarkers in Parkinson's disease. Prog Neurobiol 2011; 95: 614-628.

132. Sperling R. Potential of functional MRI as a biomarker in early Alzheimer's disease. Neurobiol Aging 2011; 32(Suppl 1): S37-S43.

133. Zeng LL, Shen H, Liu L, Wang L, Li B, Fang $P$ et al. Identifying major depression using whole-brain functional connectivity: a multivariate pattern analysis. Brain 2012; 135(Pt 5): 1498-1507.

(1) (2)(2) Translational Psychiatry is an open-access journal published by Nature Publishing Group. This work is licensed under a Creative Commons Attribution-NonCommercialShareAlike 3.0 Unported License. To view a copy of this license, visit http://creativecommons.org/licenses/by-nc-sa/3.0/ 